\title{
The Difficult Application of Modern Education Technology from the Point View of the Members of a Teaching Staff
}

\author{
Rawaa Ibrahim Issa \\ Department of Computers/College of Basic Education / \\ University of Mustansiriya \\ rawaaa_e.edbs@uomustansiriyah.edu.iq \\ Atefa Jalil Saleh \\ Department of Mathematics /College of Basic Education / \\ University of Mustansiriya \\ atefa_jalil.edbs@uomustansiriyah.edu.iq
}

ARTICLE INFO

Submission date: $11 / 4 / 2018$

Acceptance date: $14 / 6 / 2018$

Publication date: 10/3/2019

\begin{abstract}
The current research aims to identify the difficulties of using a sample of faculty members in the Faculty of Basic Education / Mustansiriya University for modern education technology in their teaching, and the extent of their actual use of the variables (academic qualification, academic qualification, specialization and years of experience). The researchers designed a research tool to identify the views of the members of the teaching staff at the Faculty of Basic Education after their distribution and to verify the validity and truthfulness of the questionnaire by presenting them to a group of arbitrators, professors of education, professors of psychology, measurement and evaluation, And a group of faculty members included in the sample of the study. The questionnaire contains the difficulties that prevent the effective use of technology from the point of view of faculty members and whether there is a relationship between variables (scientific title, specialization, academic qualification, and years of experience in university education).

The percentages, frequencies and weighted mean were used to analyze the data. The researchers also used the Wilcoxon test to identify the mean differences between the study groups using the spss program.

The results of the research revealed the existence of some obstacles that hinder the use of teaching technology by teaching staff members. The most important of these are the lack of necessary equipment and infrastructure, some of which are related to the weakness of training courses in the use of modern teaching technology in teaching. The research presented a number of recommendations and suggestions.
\end{abstract}

Key words: Education Technology, Difficulties, Wilcoxon test. 


\title{
صهوبات تطبيق تكنولوجيا التهليم الحديثة من وجهة نظر أعضاء هيئة التدريسر
}

\author{
رواء ابراهيم عيسى \\ قسم الحاسبات كلية التربية الأساسية - الجامعة المستنصرية \\ عاطفة جليل صالح \\ قسم الرياضيات -كلية التربية الأساسية -الجامعة المستنصرية صلية
}

الخلاصة

يهدف البحث الحالي إلى التعرف على صعوبات استخدام عينة من اعضاء هيئة التدريس في كلية التربية

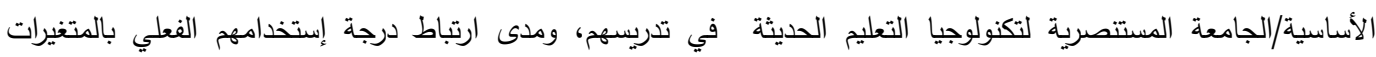

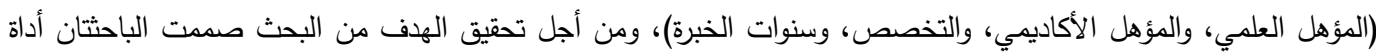

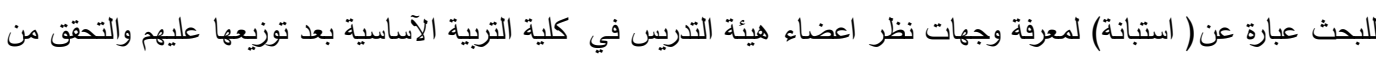

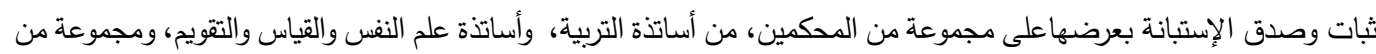

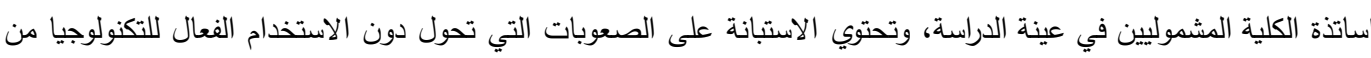

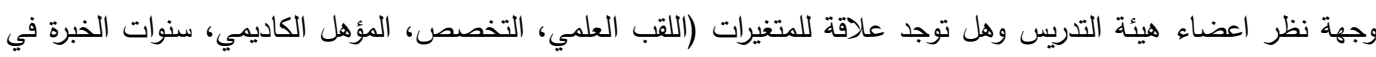

التعليم الجامعي). وقد استُتْْدِدت النسب المئوية والتكرارات والوسط المرجح لتحليل البيانات، واستخدمت الباحثنان اختبار ويكلوكسون، وذلك

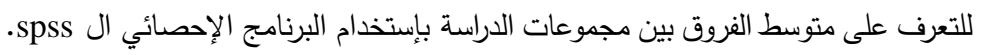

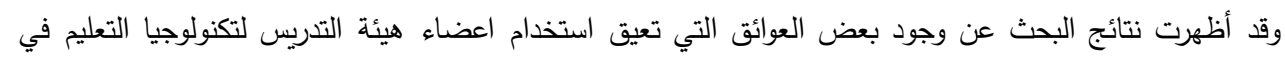
التدريس؛ كان من أهمها عدم توافر التجهيزات والبنى التحتية اللازمة، وبعضها مرتبط بضعف التيف الدورات التدريبية في كيفية توظيف تكنولوجيا التعليم الديثة في التدريس, وقد قدم البحث عددا من التوني التوصيات والمتترحات. الكلمات الدالة: تكنولوجيا التعليم الصعوبات، اختبار ويكلوكسون

\section{1- 1 - 1 مشكلة البحث}

يعتمد عمل اعضاء هيئة التدريس داخل الكلية او الجامعة بالدرجة الأولى على ناحية فنية أدائية تتمثل في دعم وتوظيف تكنولوجيا التعليم داخل القاعات الدراسية بهدف رفع مستوى جودة التعليم والارتقاء بمستوى العملية التعليمية. ويمكن تحقيق ذلك عن طريق استخدام استرا تيجيات التعلم التي تعتىد على أن يكون الطالب هو محورهذه العملية والذي تتركز حوله جميع الأنشطة التي تساعد على تحقيق الأهداف.

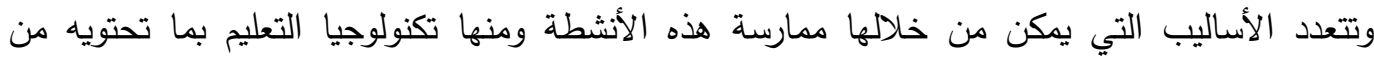

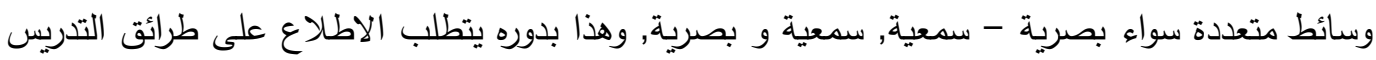

$$
\text { والاستراتيجيات الجديدة التي تتاسب مع الثورة العلمية والمعرفية. }
$$

وتكمن القيمة الأولى لـ " تكنولوجيا التعليم " وأهميتها في كونها تعد حلا لمجموعة من لهنه المشاكل

التي قد تواجه المدرسين في أثناء عمهم سواء داخل القاعة الدراسية أو خارجها. مشاكل نذكر بعضا منها: 


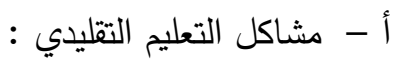

أولا : مشكلات ترتبط بالطلبة:

- كثره غياب الطلبة والتسرب بسبب ملل الطلاب من طريقة الدراسة. - ضعف القدرات البصرية والسمعية عند بعض الطلاب ( الفروق الفردية). - اختلاف مستوى الطلاب ما بين موهوبين وضعيفي الاستيعاب ( الفروق الفردية).

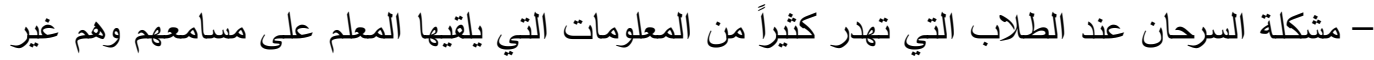
منتبهين. ثانيا : مشكلات مرتبطة بالمنهج الدراسي: - قد تكون المناهج قاصرة عن مواكبة الواقع العملي بسبب الانفجار المعرفي. - مناهج طويلة قد لا تكفي سنة دراسية لإكمالها. - شق تطبيقي ضعيف بالمقارنة مع الجانب النظري.

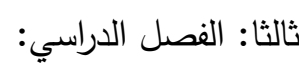
- ازدحام الفصل الدراسي وكثافة الفصول بالطلاب. - وقت الحصة ضئيل جدا بالنسبة للمنهج الدراسي.

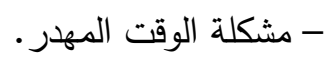

بعد سرد هذه العينة من المشاكل التي تعاني منها الفصول الدراسية في العالم العربي عامة مع فروق

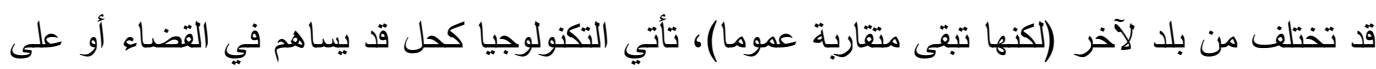
الأقل الحد منها.

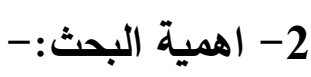

تؤدي تكنولوجيا التعليم دورا كبيرا فى مواجهة الكثير من المشكلات التربوية والتعليمية والعمل على التى تحقيق الهدف النهائي من عملية التعليم والتعلم وهو التحسين المستمر للوصوليا مولئ إلى إتقان الطلاب لمعظم المهارات وتحقيق غالبية الأهداف التعليمية.

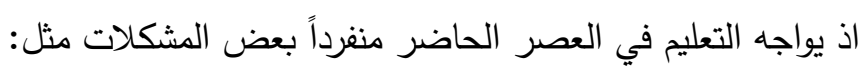
1-الزيادة الهائلة في أعداد السكان وما ترتب عليها من زيادة في أعداد المتعلمين. 2-قلة أعداد المدرسين المؤهلين تربوياً.

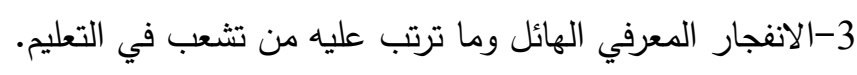

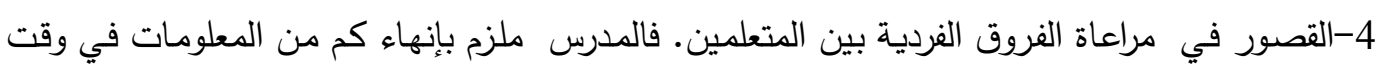

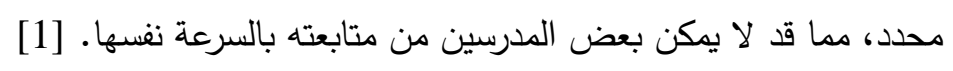

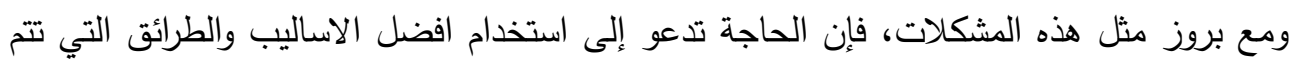
بها عملية التعليم، وتساعد على التخفيف من آثارها. تعد تكنولوجيا التعليم الحديثة من العلوم التربوية والتعليمية التي شهدت نمواً وتطوراً سريعاً في التيفي التهاء العصر الحديث، وقد أثبتت الأبحاث عظم الأكانات التي توفرها تكنولوجيا التعليم الحديثة للمؤسسة التعليمية ومدى فعاليتها في عملية التعليم والتعلم.[2] وفي ضوء ذلك تتبع اهمية البحث الحالي لعدة اعتبارات منها: 
1- أنها تعد دراسـة علمية تتتاول بشكل مفصل صعوبات استخدام تكنولوجيا التعليم الحديثة من وجهة نظر المعنيين مباشرة وهم أعضاء هيئة التدريس في الكلية. 2- الاهتمام المتزايد بتحقيق الجودة والتميز في عمليتي التعلم والتعليم، إذ يعتبر استخدام تكنولوجيا التعليم

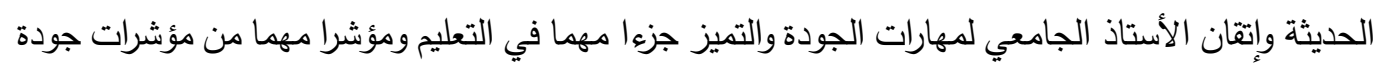
التعليم. 3- أنها تسعى إلى التعرف على المعوقات التي تحول دون استخدام تكنولوجيا التعليم في التدريس وفقا لآراء أعضاء هيئة التدريس، وتقدم مقترحات للتغلب عليها. 4-أنها تقدم التوصيات التي يمكن أن تسهم في تطوير العملية التعليمية.

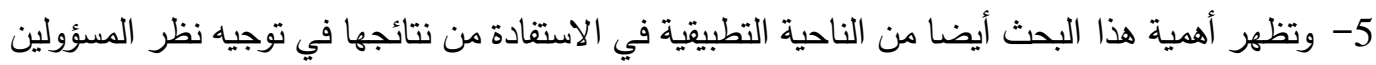
في التعليم العالي ووضعهم في صورة امام المعوقات التي تحول دون استخدام المدرسين لتكنولوجيا

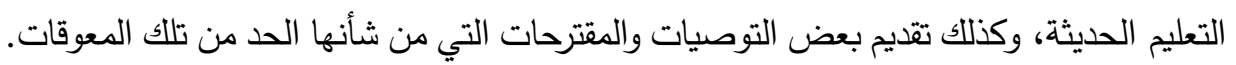
6- أن توقيت البحث الحالي يضفي أهمية خاصة إذ يتم حاليا في معظم ألأقسام في الكليات والجامعات

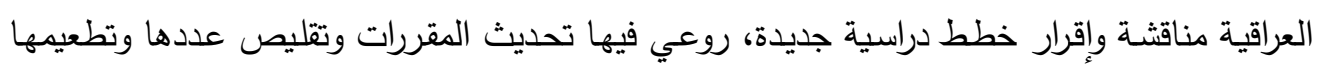
بالموضوعات ذات الصلة باحتياجات سوق العمل الذي طالما شكا من ضعف تأهيل خريجي الكليات،

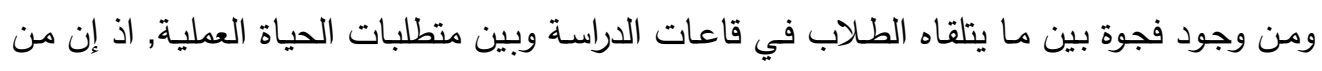

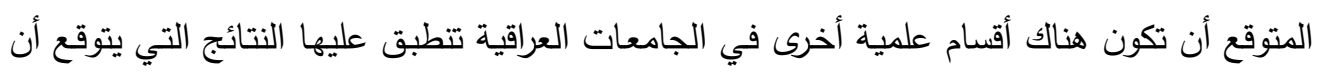
تخرج بها الدراسـة، وهذه عندئذ يمكنها أن تستقيد منها في تطوير استخدام التكنولوجيا في العملية

$$
\text { يهدف البحث الحالي الى التعرف على: }
$$

1. الصعوبات التي تواجه اعضاء هيئة التدريس في استعمال تكنولوجيا التعلم من وجهة نظرهم 2. دلالة الفرق في الصعوبات التي تواجه اعضاء هيئة التدريس في استعمال تكنولوجيا التعلم من وجهة فئسة نظرهم وفقا لمتغيرات (اللقب العلمي,التخصص,المؤهل الأكاديمي , سنوات الخبرة في التعليم الجامعي)

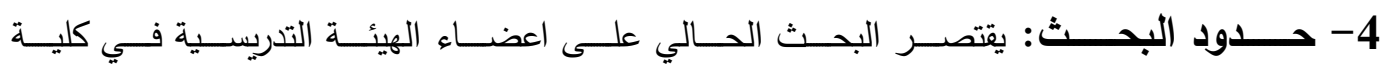

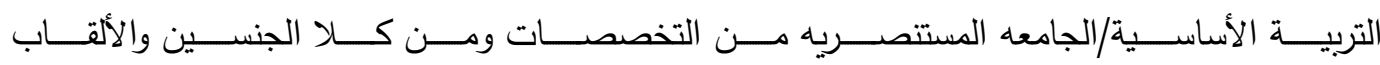
2017/2016 العلمية كافة للعام الدراسي

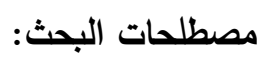
1) الصعوبات: يعرف ابو النور (1990) الصعوبات بأنها: العقبات التي تقف في طريق إتمام وإنجاح

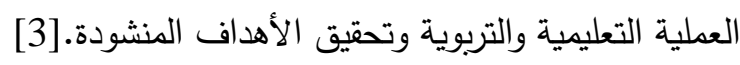
عرفها الثقفي نقلا عن معوضة بأنها مجموعة المشكلات أو المعوقات الفنية والمادية والإدارية والإثرافية التي تحول دون استخدام الددرس لطرق التدريس الحديثة في المواقف التعليمة المختلفة[4]. هي عبارة عن مجموعة من الموانع والمشكلات التي تضمنتها أداة البحث، والتي قد تحول دون استخدام المدرس لتصن للتثنيات التعليمية في قاعة المحاضرات. 
2) تكنولوجيا التعليم: عرفها (الطوبج:1988) المواد والأجهزة والمواقف التعليمية التي يستخدمها عضو هيئة التدريس في مجال الاتصال التعليمي بطريقة ونظام خاص لتوضيح فكرة أو تغيير مفهوم غامض أو شرح أحد

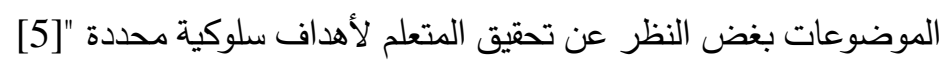
فيما يعد عطارد وكنسارة(2002) تكنولوجيا التعليم بأنها" تطبيقات العلم لحل الششاكل العلمية اي معالجة النظريات والحقائق العلمية بطريقة منظمة وشاملة يتم فيها الإفادة من الأجهزة والمواد والبرامج

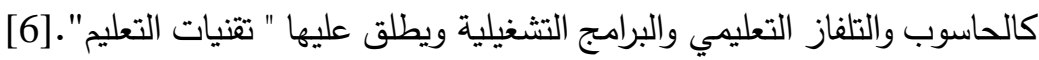
وتعرفها الباحثتان إجرائيا: "هي كل برنامج أو جهاز أو وسيلة تكنولوجية تستخدم داخل قاعة ولئيات المحاضرات من قبل الأستاذ الجامعي من أجل مساعدته في تحقيق الأهداف التعليمية المطلوبة، بطريقة شيقه وتسهيل

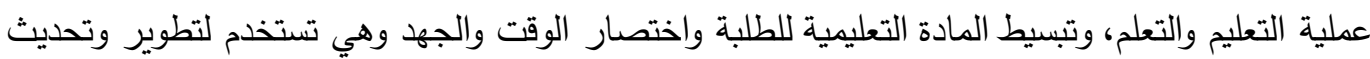
العملية التعليمية لتحقيق اهدافها بكفاءة وفاعلية". 3)عضو هيئة التدريس:- عرفهم.(عابدين،2003). " المدرسون الذين يقومون بالتدريس والبحث في وهاعة الجامعة وفي مراكزها وبرامجها المختلفة، وهم متفرغون للعمل في الجامعة ويحملون احدى الرتب العلمية من مرتبة محاضر فأعلى" [7]. ويوضح كل من(العريشي والعروان,20004)"هو الشخص الذي يقوم بالتدريس او بالتعليم والذي يحمل رتبة اكاديمية في الجامعة يطلق عليه عضو هيئة تدريس". [8ن هوران وتعرف الباحثتان عضو هيئة التدريس: هو الثخص الحاصل على شهادة الماجستير او الدكتوراه والذي يزاول مهنة التدريس في كلية التربية الأساسية والحاصل على هئ اللقب العلمي الجامعي. 5- الإطار النظري والدراسات السابقة:تكنولوجيا التعليم :-

التكنولوجيا كلمة مركبة تثير إلى العلم الذي اهتم بتحسين الأداء والصياغة أثناء التطبيق العملي.

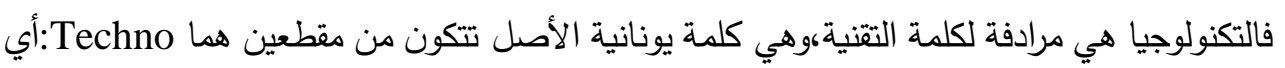
حرفة أو صنعة أو فن، و Logy بمعنى علم، ويمكن أن تكون كلمة تكنولوجيا مشتقة من الكلمة الإنجليزية Technique بتطبيق النظريات، ونتائج البحوث التي تم التوصل إليها في مجالات العلوم المختلف؛؛ بهدف تطوير الأداء، ورفع معدلات الكفاءة] [9]. وعرفت اليونسكو التتنيات التعليمية(تكنولوجيا التعليم) بأنها منحى نظامي لتصميم العملية التعليمية

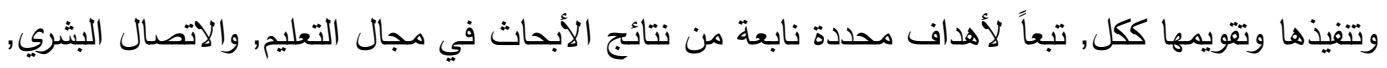

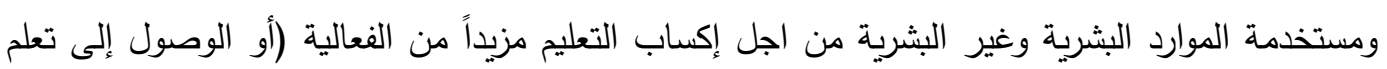
أفضل, وأكثر فعالية). [10] وقد أورد سلامة والدايل (2008) عدة تعاريف لتكنولوجيا التعليم، منها[11]: - تعريف تشارلز هوبان (Hoban) الذي ينص على "أنها تتظيم متكامل يضم الإنسان والآلة والأفكار والآراء وأساليب العمل والإدارة، بحيث تعمل داخل إطار واحد." - وكذلك اشار كلارك ( Clark )على "أنها عملية الاستفادة من المخترعات والصناعات الحديثة في مجال التعليم." - n - n 
- ويعدها بريقز (Briggs) على أنها "تتألف من ثلاثة عناصر هي:

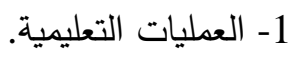
2-الأدوات والأجززة والبرمجيات المستخدمة في العملية التعليمية. 3-تفاعل العمليات مع الأجهزة والأدوات.

لذا فإن تكنولوجيا التعليم أكبر من مجرد وسيلة تعلم أو جهاز أو أداة أو أسلوب أو نظام؛ لأنها تحتوي على الأى

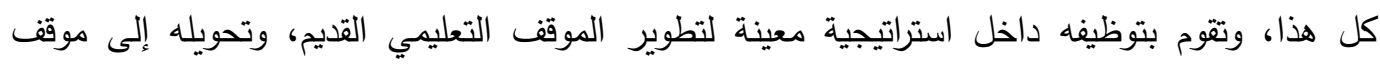
تعليمي حديث يكون للمتعلم دورا أساسيا فيه، من خلال إجراءات التعليم، وترتب أحداثه، وتقويمه بشكل دئه

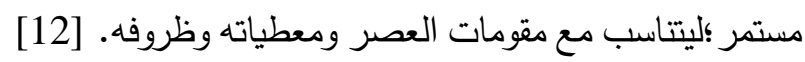
6 - أهمية التكنولوجيا في مجال التعليم : 1- تلعب التكنولوجيا دور المرشد الذي يساعد المعلم في توجيه المادة العلمية للطالب.فالتكنولوجيا تستطيع أن تغير شكل تقديم الدروس للطالب على نحو يعطي فرصة أكبر وأسهل في الفهم والتعلم.

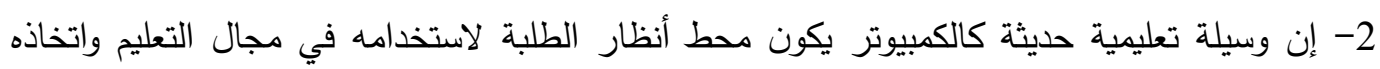
كمرشد أو معلم إلكتروني مساعد يرشدهم ببرامجه المتتوعة ووظائفه المختلفة في مجال التعلم. 3- كذللك يفتح الإنترنت بابا جديدا يساعد الطلبة في الفصل الواحد أن يشتركوا في أنشطة تعليمية مختلفة في مجال البحث وتبادل المعلومات من خلال هذه الأنشطة. 4- توفر التكنولوجيا مصدرا غزيرا من المعلومات التي يحتاج لها المعلم والطالب على حد سواء.

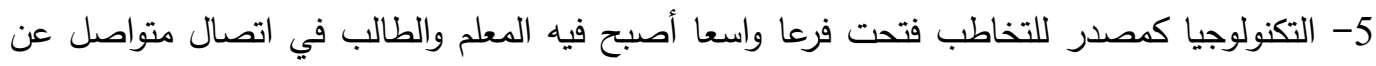
طريق التحدث عبر شبكة الإنترنت.

\section{7- أهمية استخدام تكنولوجيا التعليم في التدريس الجامعي:}

إن استخدام الوسائل التعليمية يمكن أن يساعد على تحقيق الأهداف التدريسية، وتشويق الطلبة، التهائ

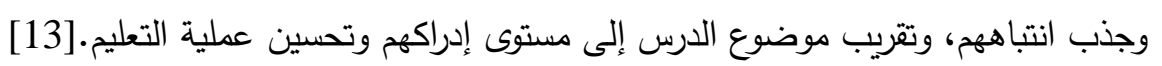

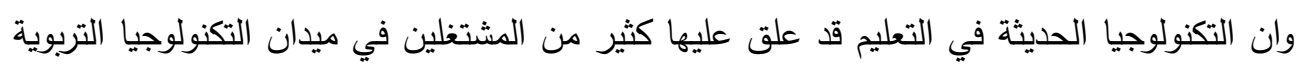

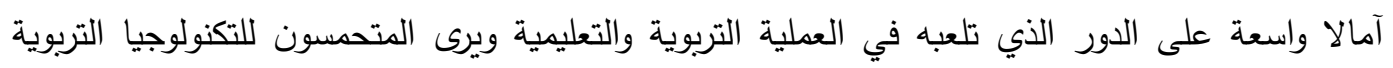
والتعليمية أن استخدامها سوف يؤدي إلى مايلي: 1- تضع الطلبة في مواقف محفزة للتفكير و تتمية القدرة على التأمل والتثكير العلمي الخلاق في الوصول

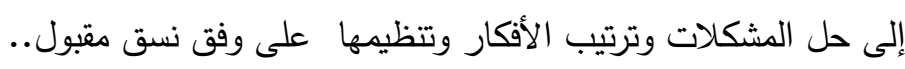

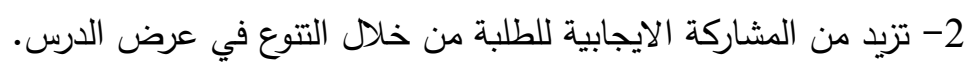
3- تساعد عضو هيئة التدريس على حسن عرض الايجابة المادة واستغلال وقت من التدريس بشكل أفضل. 4- تختصر وقت التدريسي وجهده في الأعداد والتنفيذ للدرس.

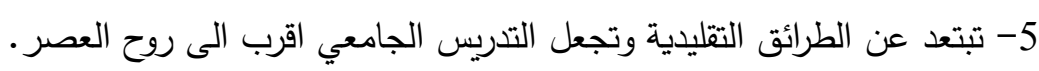
6- تعمل على مراعاة الفروق الفردية بين الطلبة. 7- تهيئ الفرصة لتحقيق التعلم الذاتي والفردي للطالب. 8-ترفع انتاجية المؤسسة التعليمية كما ونوعاً. 9- تثير دافعية المتعلم وإهتمامه وتشوقه للتعلم. 
10-تساعد على التذكر وسرعة التعلم وتعمل على تتبيته.

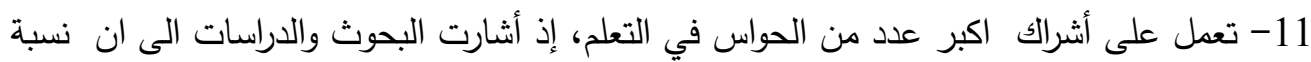
تذكر الفرد تختلف باختلاف الحاسة أوالحواس المستخدمة في التعلم وأن الفرد يستطيع تذكر :-

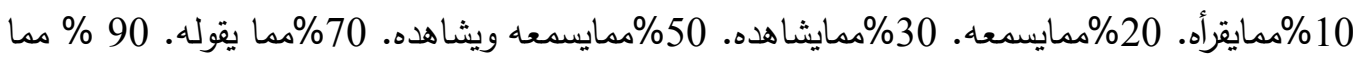
يقوله أثناء أدائه عملا معينا. [14 12- مواجهة النقص في أعداد هيئة التدريس المؤهلين علمياً وتربوياً 13- التغلب على مشكلة تضخم المناهج والمقررات الدراسية 14- تحقيق هدف العملية التعليمية اليوم، والرامي إلى تتمية الاتجاهات الجديدة وتعديل السلوك.

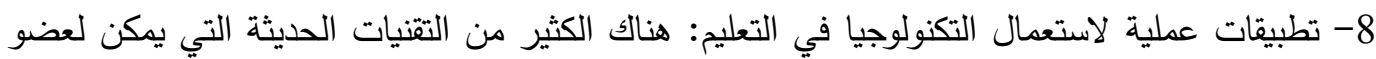

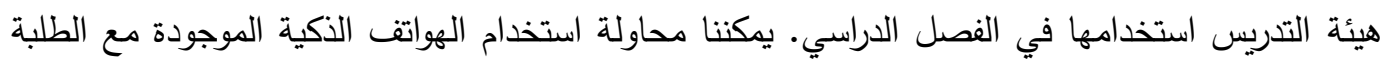
لتلبية الرغبة لاستكثاف التكنولوجيا، وتعزيز استخدام التقنية في الفصول الدراسية. هذه طرائق سهلة و بسيطة يمكن اتباعها من طرف عضو هيئة التدريس للعمل على إدخال التكنولوجيا إلى الفصول الدراسية ومنها: 1 - السبورة الذكية ( السبورة التفاعلية ) SMART Boards: تعد السبورات الذكية Smart: Board السبورات التفاعلية البيضاء كبيرة المساحة، والحساسة للمس. ويتم استخدامها لعرض ما على شاشة

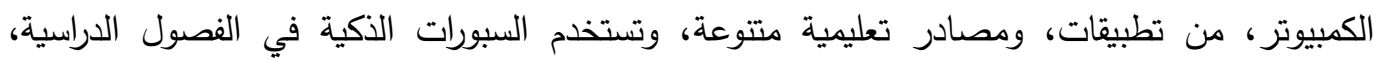
وقاعات المحاضرات، والاجتماعات، والمؤتمرات، والندوات، وورش العمل، وتستخدم في والتواصل من ون

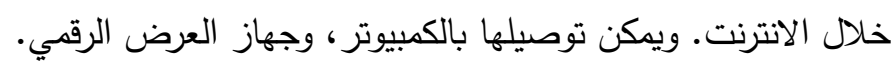

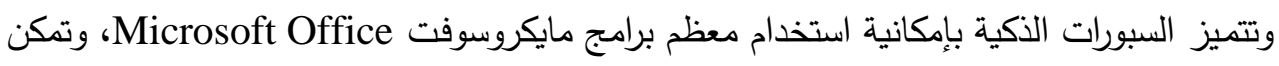
من الإبحار في الانترنت بكل حرية مما يسهم بشكل مباشر في إثراء المادة العلمية من خلال إضافة أبعاد ومؤثرات خاصة وبرامج مميزة تساعد في توسيع خبرات المتعلمين، وتيسير بناء المفاهيم، واستثارة اهتمام

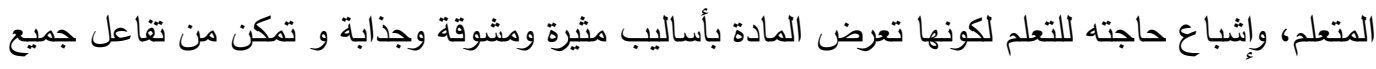
المتعمين مع الوسيلة خلال عرضها وذلك من خلال إتاحة الفرصة لمشاركة بعض المتعلمين في استخدام الوسيلة ويترتب على ذلك بقاء أثر التعلم، مما يؤدي بالضرورة إلى تحسين نوعية التعلم ورفع معدل الأداء عند الطلبة أو المتدربين. 2- الوسائط الاجتماعية Social Media : يمكن استخدام شبكات التواصل الاجتماعي مثل فيسبوك

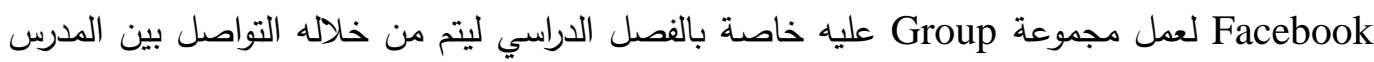
والطلاب. فيمكن للددرس أن ينشر على هذه المجموعة المقالات المثيرة للاهتمام الموجودة في أنحاء الإنترنت المختلفة، جنبا إلى جنب مع تحديثات الفصول الدراسية، والتواصل مع أولياء الأمور وتقديم لمحات عما يدرسه الطلبة.

3- البريد الإكتروني، ورسائل شبكات التواصل الاجتماعي Email \& Social Media Messaging

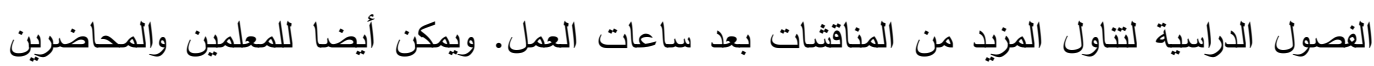


التواصل مع الطلاب بشكل من خلال عناوين الاتصال الخاصة بشبكات التواصل الاجتماعي لتقليل المخاوف التي قد تجعل الطلاب لا يرغبون في المشاركة. 4- يوتيوب YouTube:ثيثل موقع يوتيوب (YouTube )ثروة لملفات الفيديو التعليمية، ويمكنك أيضا تسجيل محاضرات المدرس ودروسه الخاصة ورفعها على قنات الكلية اوالجامعة او موقع وزارة التعليم.

5- الفيديو: يلعب الفيديو دوراً كبيراً كعنصر من عناصر تقنيات التعليم، فهو يعطي المتعلمين إيحاء

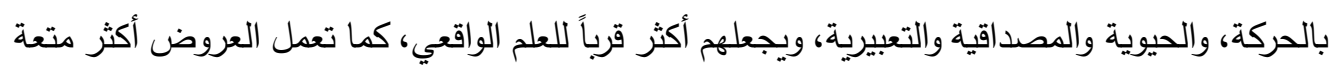
وإثارة عند مشاهدتهاواستخدامها.

ويعد كنسارة وعطار (2009) الفيديو أقوى الوسائل التعليمية التي استخدمتها العملية التعليمية في

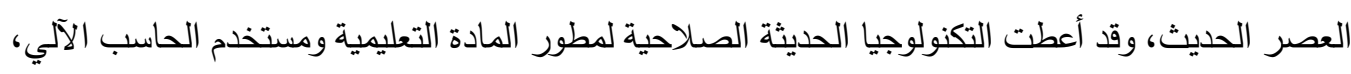

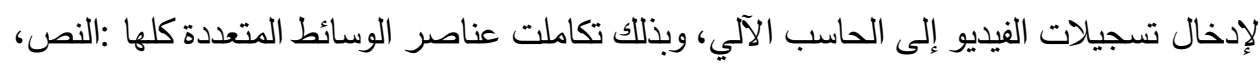
الصوت، الصورة،الحركة. [16] 6- جهاز عارض البيانات: بدأ استخدام جهاز عرض البيانات حديثاً في المؤسسات التعليمية، وزاد استخدامه

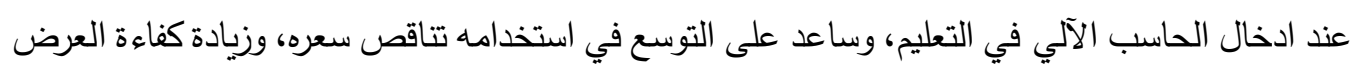

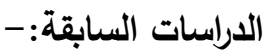

1) دراسة(مرسي وعلي، 1993 ) والتي هدفت إلى الكثف عن اتجاهات معلمي المواد العلمية في المرحلة الثانوية نحو استخدام تكنولوجيا التعليم في منطقة عمان الكبرى في الأردن، ولتحقيق هذا الهدف أعدى أعد الباحث

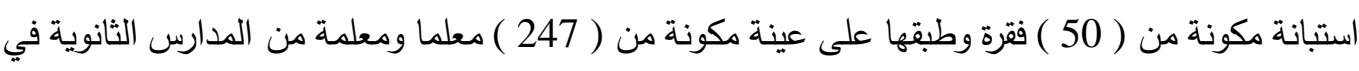

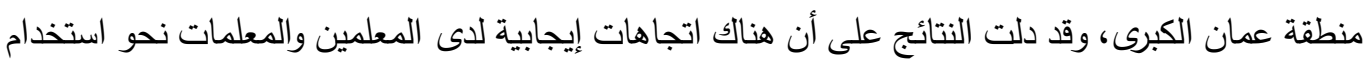

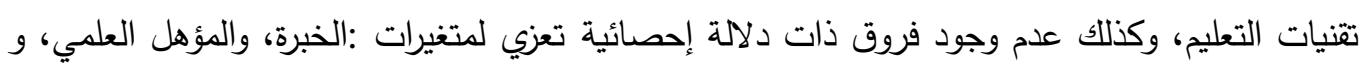
أشارت النتائج إلى أن معوقات استخدام الأجهزة والمواد التكنولوجية تتمثل في قلة التحائلة الدعم المالي والإداري.

2) دراسة سميث (171) (1996,Smith ) والتي هدفت إلى معرفة العلاقة بين اتجاهات معلمي المرحلة الثانوية نحو استخدام تكنولوجيا التعليم واستخدامها الفعلي، ولتحقيق ذلك أعد الباحث مقياسا للاتجاهات بطريقة

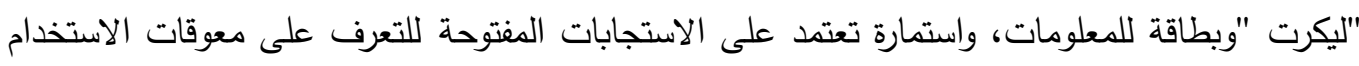
الفعلي لتكنولوجيا التعليم، وقد توصلت الدراسة للنتائج التالية: - هناك علاقة دالة إحصائيا بين مستوى التدريب على التكنولوجيا والإلمام بها وكل من الاتجاه والاستعمال الفعلي لتكنولوجيا التعليم. لا توجد علاقة دالة إحصائيا بين متغيرات الجنس والعمر والخبرة التدريسية، والتخصص العلمي واتجاه

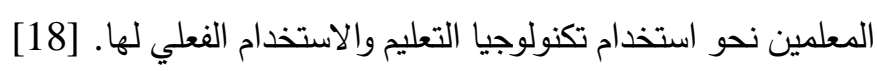
وجاءت دراسـة خزاعلة وجوارنـة ( Khazaleh \& Jawarneh, 2006 ) بهدف الكثف عن معوقات التوظيف الفعال لتكنولوجيا المعلومات في المدارس الأردنية من خلال تحليل تصورات المعلمين في الميدان .

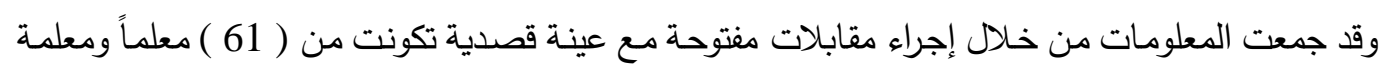

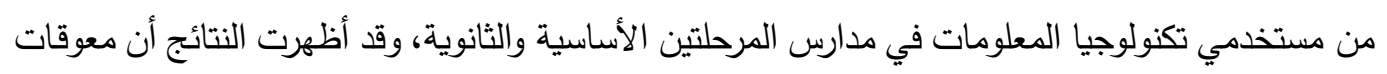


التوظيف الفعال لتكنولوجيا المعلومات في المدارس الأردنية تقع في ست مجموعات رئيسة، هي :النقص الحاد

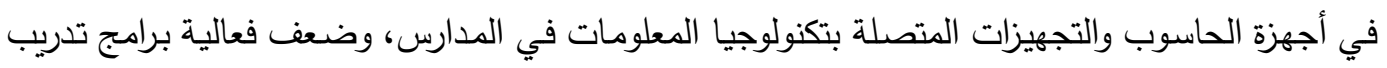
المعلمين في مجال تكنولوجيا المعلومات، وقلة امتلاك طلبة المدارس لمهارات وكفايات تكنولوجيا المعلومات الأساسية، وقلة كفاية الوقت اللازم للمعلمين للتخطيط والإعداد لتوظيف تكنولوجيا المعلومات في التدريس،

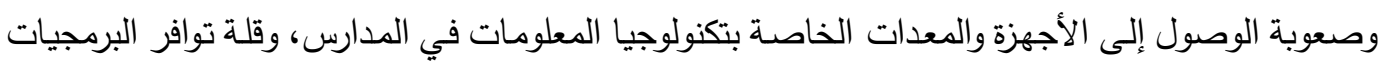

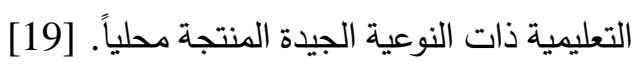
وأجرى العمايرة (2003) دراسة هدفت التعرف على آراء معلمي بعض مدارس وكالة الغوث الدولية في الأردن

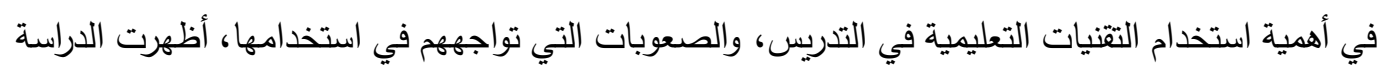

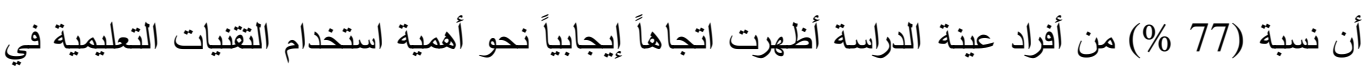

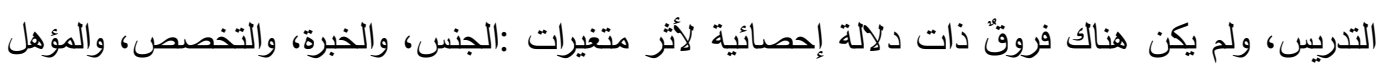

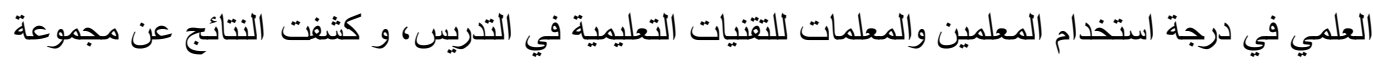

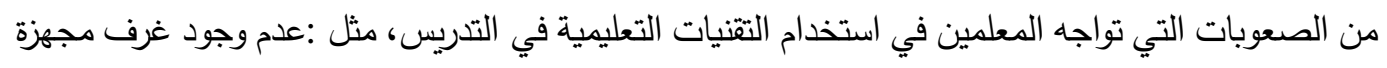
لاستخدام التقنيات التعليمية، وعدم توافر العدد الكافي من الأجهزة التعليمية اللازمة للتدريس في المدرسة،

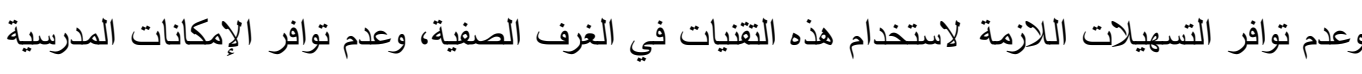

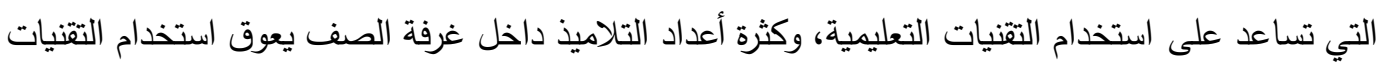
التعليمية بشكل فاعل. [20]

\section{تعقيب على الاراسات السابقة:}

- أشارت بعض الدراسات إلى قصور كبير في مستوى استخدام أعضاء هيئة التدريس لتقنيات التعليم، وهذا

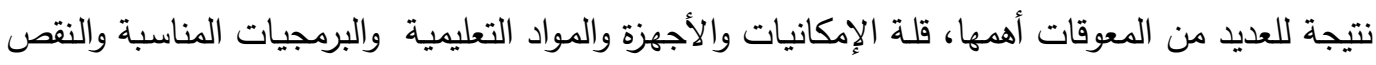
في التدريب على الاستخدام الأمثل لتقنيات التعليم، ومن تللك الدراسات،(مرسي وعلي، 1993)، (خزاعلة وجوارنة، 2006).

- أشارت الدراسات إلى عدم تأثير متغير المؤهل العلمي، والخبرة، الجنس،المؤهل الأكاديمي، التخصص على درجة استخدام تقنيات التعليم. - اشتركت الدراسـة الحاليـة مـع الدراسـات السـابقة بكثير من النقاط مثل المنهج المستخدم وهو المنهج الوصفي, وكذللك العينة المستهدفة وهي المعلمين، وتميزت عنها إنها طبقت على عينة مختلفة وهي اعضاء هيئة التدريس وكذلك مكان التطبيق وله مايميز البحث الحالي عن الاراسات السابقة:

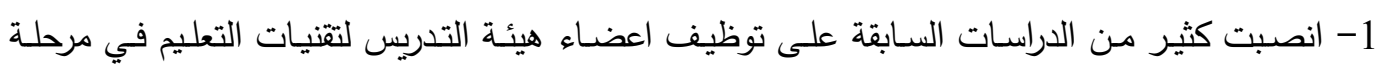
التعليم الأساس او المرحلة الثانوية، في حين قلت هذه الدراسات في المرحلة الجامعية. 2-لم يتم التطرق لمثل هذه الدراسة في حدود علم الباحثين على المستوى المحلي في الجامعات العراقية، مما يزيد من اهمية البحث. 


\section{9- منهج البحث والإجراءات:}

منهج البحث: استخدمت الباحثتان في هذا البحث المنهج الوصفي التحليلي، وهو المنهج الذي يهتم بوصف

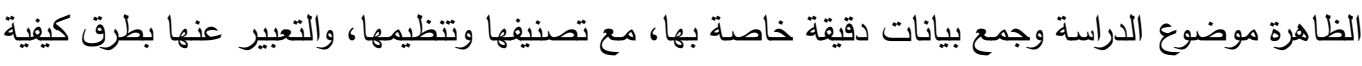

وكمية، بحيث يؤدي ذلك إلى الوصول إلى استتتاجات وتعميمات تساعد في تطوير الواقع. [21]

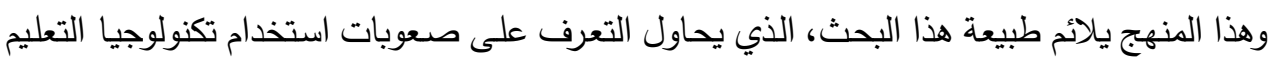

$$
\text { في التدريس الجامعي. }
$$

مجتمع البحث وعينته: تكون مجتمع الدراسة من عينة عشوائية من اعضاء هيئة التدريس في الأقسام

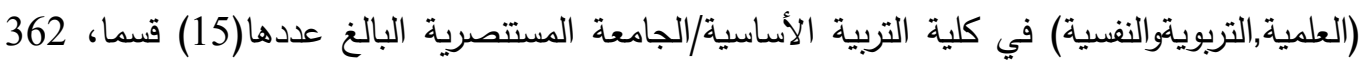
عضوا تدريسيا، 170 عضوا تدريسيا من الذكور، 192 عضو تدريسية من الأناث.

عينة البحث: أما عينة البحث تكونت من (100) عضوا تدريسيا موزعة كما هو مبين في الجدول (1) حيث كانت العينة تمثل 30\% من العينة الكلية لمجنمع البحث.

جدول (1): توزيع أفراد عينة البحث حسب الخبرة التدريسية والمؤهل العلمي والتخصص

\begin{tabular}{|c|c|c|c|c|c|c|c|}
\hline \multicolumn{2}{|c|}{ سنوات الخبرة } & \multicolumn{2}{|c|}{ التخصص } & \multicolumn{2}{|c|}{ المؤهل الأكاديمي } & \multirow[t]{2}{*}{ المؤهل العلمي } & \multirow[t]{2}{*}{ ت } \\
\hline 6سنوات فأكثر & 1-5سنوات & انساني & علمي & دكتوراة & ماجستير & & \\
\hline 1 & 17 & 10 & 8 & --- & 18 & مدرس مساعد & 1 \\
\hline 53 & --- & 26 & 27 & 29 & 24 & مدرس & 2 \\
\hline 20 & --- & 11 & 9 & 18 & 2 & استاذمساعد & 3 \\
\hline 9 & --- & 9 & --- & 9 & ---- & استاذ & 4 \\
\hline \multicolumn{2}{|c|}{100} & \multicolumn{2}{|c|}{100} & \multicolumn{2}{|c|}{100} & \multicolumn{2}{|c|}{ لمجموع } \\
\hline
\end{tabular}

اداة البحث : لغرض التحقق من اهداف البحث لابد من توافر اداة لقياس الففهوم المراد قياسه ووفقا لطبيعة

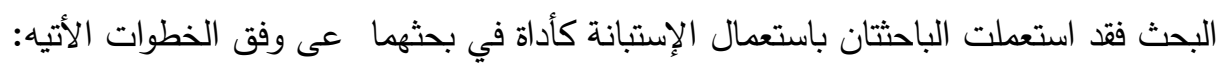

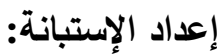

مر إعداد الاستبانة بالخطوات التالية:

أ- تحديد الههف من الاستبانة: تم إعداد استبانة بهدف قياس صعوبات استخدام تكنولوجيا التعليم الحديثة التي تتضمنها القائمة في التدريس وذلك طبقا للبدائل المتضمنة بكل منها (نعم، احيانا، كلا) ودرجاتها على لهي الترتيب (1،2،3) ب- صدق الاستبانة: للتأكد من صدق الاستبانة تم عرضها على مجموعة من السادة المحكمين في مجال

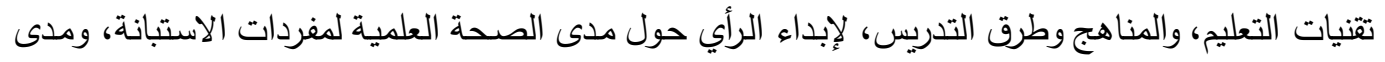

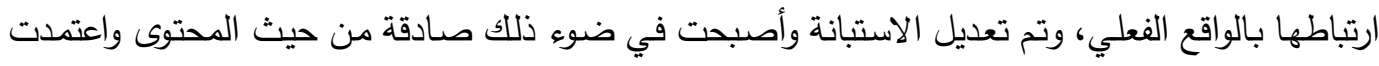

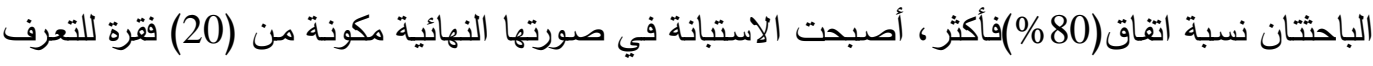
على صعوبات استخدام تكنولوجيا التعليم في التدريس الجامعي. 
ج- ثبات أداة البحث: باستخدام معامل" ألفا كرونباخ (Cronbach Alpha) "جاءت قيمة معامل الثبات الكلي)(0.87 ) ، وتثير هذه القيمة العالية من معاملات الثبات إلى صلاحية الاستبانة للتطبيق وإمكانية الاعتماد على نتائجها والوثوق بها. المعالجة الإحصائية : لقد تمت المعالجة الإحصائية للبحث بإستخدام البرنامج الإحصائي (spss )، حيث

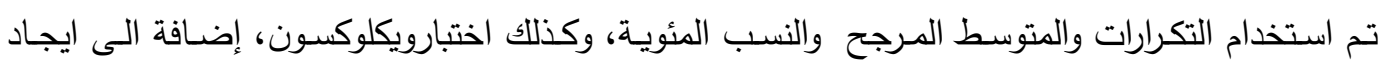
معامل الإرتباط في ثبات ادوات البحث. 1) الوسط المرجح:لحساب حدة الصعوبة, فقد اعطيت ثلاث درجات للبديل الأول صعوبة كبيرة, ودرجتان للبديل الثاني صعوبة متوسطة, ودرجة واحدة للبديل الثالث لاتثكل صعوبة.

$$
\begin{aligned}
& 1{ }^{*}{ }_{3} ت+2{ }_{2} ت+3{ }_{1}{ }_{1} \\
& \text { الوسط المرجح }=
\end{aligned}
$$

2) الوزن المئوي: لبيان القيمة النسبية لكل متغير من متغيرات الدراسة وللإفادة منه في تفسير النتائج

$$
\text { الوسط المرجح }
$$

\% 100 , الدرجة القصوى تساوي (3) في المقياس الثلاثي, [22]

$$
\text { و - الدرجة القصوى }
$$$$
\text { الوزن المئوي = }
$$

معادلة اختبار ويكلوكسون للعينات (ن > 50) $=د(3$

$$
\frac{\sqrt{(1+ن 2)(1+\dot{u})}}{24}
$$

$$
\text { 10- نتائج البحث ومناقشتها: }
$$

حاول البحث التحقق من الأهداف التالية :

1) التعرف على صعوبات استخدام تكنولوجيا التعليم في التدريس الجامعي من وجهة نظر اعضـاء التهاء

$$
\text { الهيئة التدريسية. }
$$

اظهر التحليل الإحصائي للبيانات بان الصعوبات توزعت كما في الجدول التالي: 
جدول(2): استجابات افراد العينة على فقرات الإستبانة توضح التكرارات والوسط المرجح والوزن المئوي

\begin{tabular}{|c|c|c|c|c|c|c|}
\hline \multirow{2}{*}{ 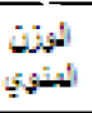 } & \multirow{2}{*}{ 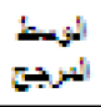 } & \multicolumn{3}{|c|}{$\Delta \cup$ 슨 } & \multirow{2}{*}{0} & \multirow[b]{2}{*}{ 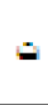 } \\
\hline & & 35 & 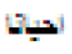 & تصن & & \\
\hline 58 & 1.73 & 49 & 29 & 22 & A & 1 \\
\hline 61 & 1.84 & 34 & 48 & 18 & 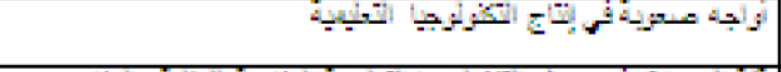 & 2 \\
\hline 94 & 2.83 & 1 & 15 & 84 & . & 3 \\
\hline 99 & 2.97 & 1 & 1 & 98 & 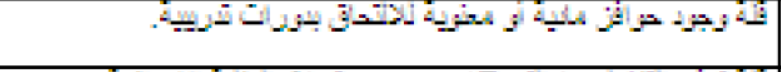 & 4 \\
\hline 91 & 2.73 & zero & 27 & 73 & 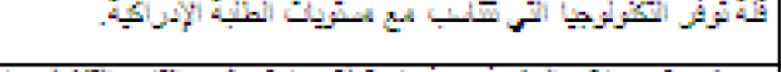 & 5 \\
\hline 68 & 2.03 & 21 & 55 & 24 & 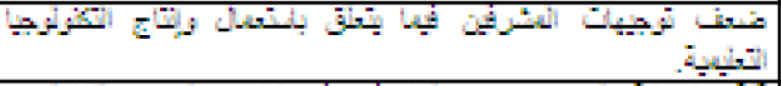 & 6 \\
\hline 79 & 2.38 & 11 & 40 & 49 & 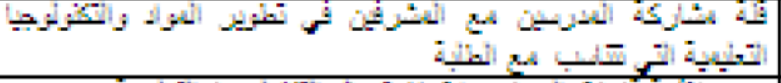 & 7 \\
\hline 97 & 2.91 & 3 & 3 & 94 & 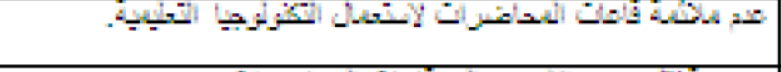 & B \\
\hline 96 & 2.9 & 3 & 4 & 93 & 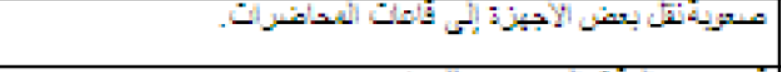 & 9 \\
\hline 79 & 2.36 & 25 & 14 & 61 & 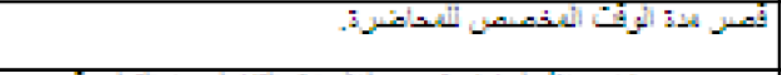 & 10 \\
\hline 89 & 2.66 & 9 & 15 & 75 & 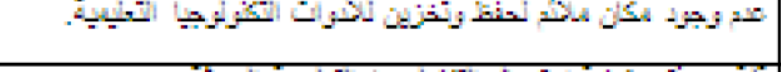 & 11 \\
\hline 54 & 1.63 & 47 & 43 & 10 & 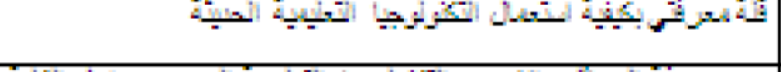 & 12 \\
\hline 63 & 1.9 & 37 & 96 & 27 & 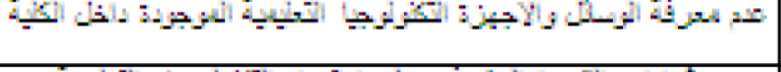 & 13 \\
\hline 50 & 1.5 & 67 & 15 & 17 & 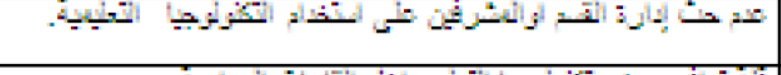 & 14 \\
\hline BB & 2.65 & 5 & 25 & 70 & 4 - & 15 \\
\hline 69 & 2.06 & 29 & 95 & 35 & 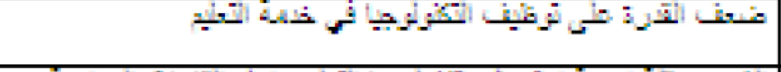 & 16 \\
\hline 71 & 2.14 & 32 & 22 & 45 & 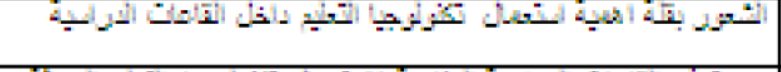 & 17 \\
\hline 93 & 2.78 & 8 & 6 & 36 & 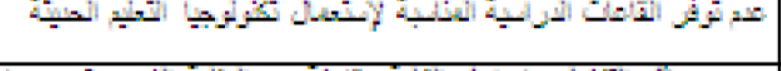 & 18 \\
\hline 79 & 2.38 & 27 & 8 & 65 & 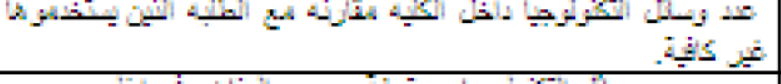 & 19 \\
\hline 83 & 2.49 & zero & 51 & 49 & 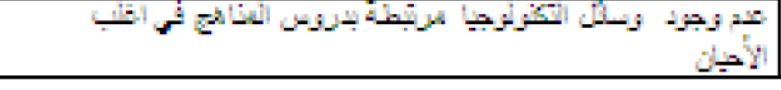 & 20 \\
\hline
\end{tabular}

رتبت الصعوبات تتازليا جدول(3) من اكثر الصعوبات حدة الى اقل الصعوبات حدة وكانت قلة وجود الحوافز المادية والمعنوية اذ بلغت حدتها (2.97) ووزن مئوي (99\%) وقلة الدورات التدريبية في مجال التكنولوجيا،عدم ملائمة وتوفر قاعات المحاضرات الملائمة لاستعمال التكنولوجيا التعليمية ضمن الثلث الأعلى (33\%) لأنها تمثل اهم الصعوبات من وجهة نظر اعضاء هيئة التدري. وهذا النتيجة متفقة مع دراسة كل من (مرسي وعلي، 1993 )، (خزاعلة وجوارنة، 2006). 
جدول(3)

\begin{tabular}{|c|c|c|c|c|c|c|}
\hline \multirow{2}{*}{ |نئزئة } & \multirow{2}{*}{ |lit } & \multicolumn{3}{|c|}{$\Delta$ - } & \multirow{2}{*}{ 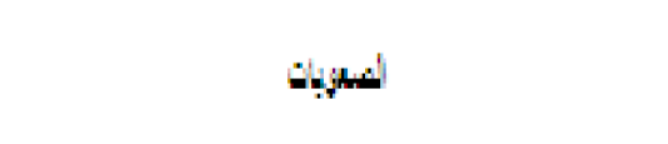 } & \multirow[b]{2}{*}{$=$} \\
\hline & & $y$ & 4 & i & & \\
\hline 58 & 1.73 & 49 & $2 \theta$ & 22 & 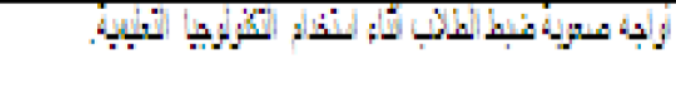 & 1 \\
\hline 61 & 1.84 & 34 & 48 & 18 & 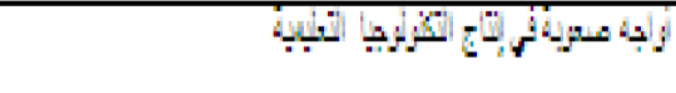 & 2 \\
\hline 94 & 2.83 & 1 & 15 & 84 & 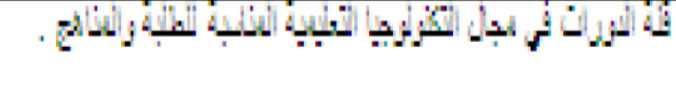 & 3 \\
\hline 99 & 2.97 & 1 & 1 & 98 & 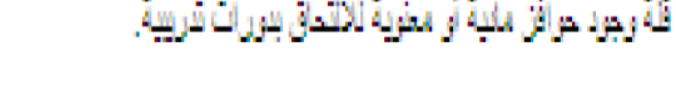 & 4 \\
\hline 91 & 2.73 & 200 & 27 & 73 & 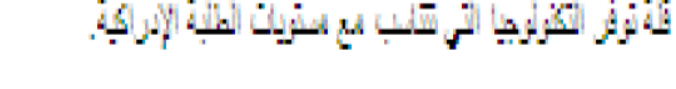 & 5 \\
\hline 68 & 2.03 & 21 & 5 & 24 & 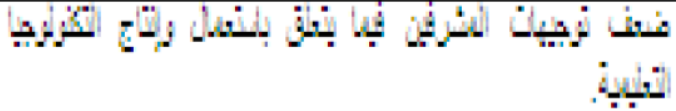 & 6 \\
\hline 79 & 2.38 & 11 & 4. & 48 & 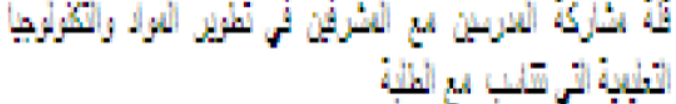 & 7 \\
\hline 97 & 2.91 & 3 & 3 & 94 & 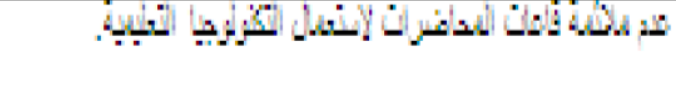 & 8 \\
\hline 96 & 2.9 & 3 & 4 & 9 & 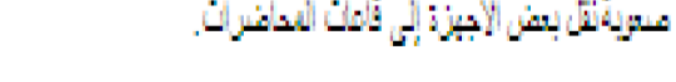 & 9 \\
\hline 79 & 2.36 & 25 & 14 & 61 & 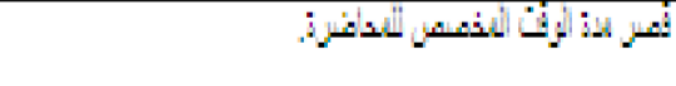 & 10 \\
\hline 89 & 2.66 & 9 & 16 & 75 & 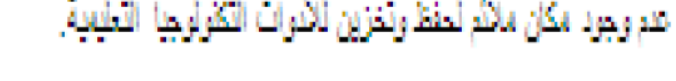 & 11 \\
\hline 54 & 1.63 & 67 & 43 & 10 & كئرة & 12 \\
\hline 63 & 1.9 & 37 & 8 & 27 & 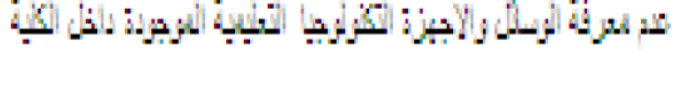 & 13 \\
\hline 50 & 1.5 & 67 & 16 & 17 & 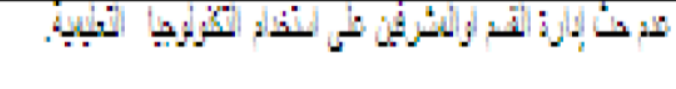 & 14 \\
\hline 88 & 2.65 & 5 & 25 & 70 & 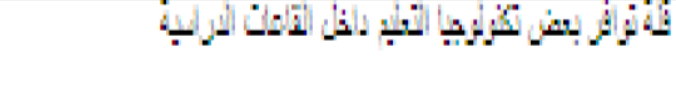 & 15 \\
\hline 69 & 2.06 & 2 & 8 & 35 & 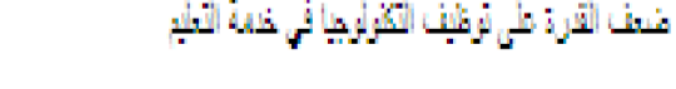 & 16 \\
\hline 71 & 2.14 & 3 & 22 & 45 & 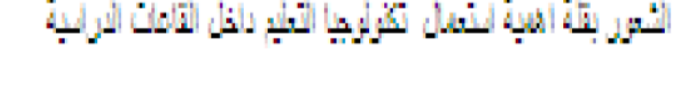 & 17 \\
\hline 93 & 2.78 & 8 & 6 & 8 & ثل نز & 18 \\
\hline 79 & 2.38 & 27 & 8 & 6 & 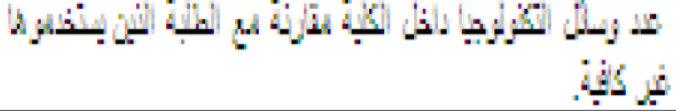 & 19 \\
\hline 83 & 2.49 & 280 & 51 & 4 & 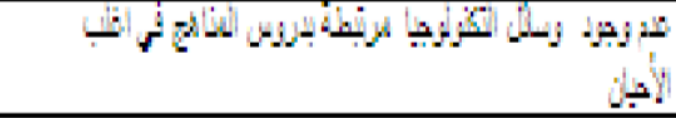 & 20 \\
\hline
\end{tabular}


للتعرف على متوسط الفروق لصعوبات استخدام تكنولوجيا التعليم في التدريس الجامعي من وجهة نظر اعضاء الهيئة التدريسية وفقا لمتغير المؤهل العلمي.

اظهر التحليل الإحصائي للبيانات بان الصعوبات توزعت كما في الجدول(4) التالي: 1) تم حساب الوسط المرجح والوزن المئوي لصعوبات استخدام تكنولوجيا التعليم من وجهة نظر أعضاء لأنياء هيئة التدريس(عينة البحث) وذلك بحسب متغير المؤهل العلمي، فجاءت النتائج كما هي موضحة في وجئ جدول(4). جدول(4):ترتيب الصعوبات والأوزان المئوية بحسب متغير المؤهل العلمي

\begin{tabular}{|c|c|c|c|c|c|c|c|c|}
\hline \multicolumn{2}{|c|}{ I } & \multicolumn{2}{|c|}{ IE } & \multicolumn{2}{|c|}{ axy } & \multicolumn{2}{|c|}{ 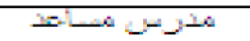 } & \multirow[t]{2}{*}{ التسبربات } \\
\hline المبنوين & 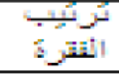 & الدئني & إن & النولئني & |ن & 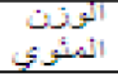 & | & \\
\hline 100 & 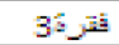 & 100 & $3^{2} \mathrm{j}^{-3 \mathrm{i}}$ & 99 & $45 \mathrm{jin}$ & 98 & 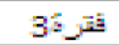 & 1 \\
\hline 100 & $45 \mathrm{j}^{\mathrm{i}}$ & 100 & $46 \mathrm{j}^{\mathrm{i}}$ & 97 & 85, & 98 & 48 _是 & 2 \\
\hline 100 & 52 每 & 100 & 86 Ji & 96 & 96 登 & 98 & 15 Jil & 3 \\
\hline 100 & 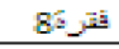 & 100 & 96 & 91 & $18 \%$ ji & 93 & 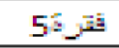 & 4 \\
\hline 100 & $96 \mathrm{j}^{\mathrm{in}}$ & 100 & $186 \mathrm{j}^{\mathrm{i}}$ & 90 & 35, 汪 & 93 & 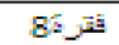 & 5 \\
\hline 100 & 106 & 98 & 53 望 & 87 & 113 年 & 93 & 96 烈 & 6 \\
\hline 100 & 11: & 98 & $112 \mathrm{ji}$ & 86 & $5:$ 酒 & 87 & $18 \% \mathrm{ji}$ & 7 \\
\hline 100 & 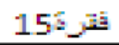 & 90 & $176 \mathrm{j}$ & 85 & $15 \mathrm{j}$ & 83 & $196 \mathrm{~J}$ & 8 \\
\hline 100 & $18 \%$ ر & 88 & $196 \mathrm{j}$ & 84 & 206 jis & 83 & 206 Jis & 9 \\
\hline 81 & 206 & 83 & $15 \%$ is & 82 & $106{ }^{6}$ & 78 & 165 & 10 \\
\hline 78 & 78 i & 80 & $206 \mathrm{j}$ & 82 & $78 \mathrm{~J}^{3}$ & 76 & 76 年 & 11 \\
\hline 78 & 135 ت & 78 & $7{ }^{2}$ & 75 & 196 & 76 & $11{ }^{2}$ & 12 \\
\hline 78 & 17: & 73 & 15ز & 72 & $2=3$ & 70 & 135 & 13 \\
\hline 78 & 196ر & 73 & 65 & 70 & 65 这 & 67 & 106 型 & 14 \\
\hline 67 & $65 \mathrm{j}^{\mathrm{i}}$ & 63 & $106 \mathrm{j}$ & 69 & $166 \mathrm{j}^{\mathrm{i}}$ & 63 & 25 , 豆 & 15 \\
\hline 67 & 168 & 62 & 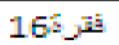 & 67 & 135 je & 61 & 125 每 & 16 \\
\hline 56 & 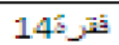 & 53 & $14 z_{j} \mathrm{ji}$ & 67 & 175 ji五 & 61 & 175 ji & 17 \\
\hline 44 & $13 \mathrm{j}$ & 52 & $135 \mathrm{ji}$ & 60 & 125,3 & 56 & 63 型 & 18 \\
\hline 33 & $25 \mathrm{j}$ & 43 & 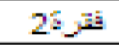 & 55 & 15 每 & 54 & 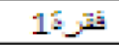 & 19 \\
\hline 33 & 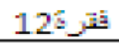 & 42 & 125 这 & 47 & 145 j迋 & 54 & 148 帮 & 20 \\
\hline
\end{tabular}

وبتطبيق خطوات اختبار ويكلوكسون بين (مدرس مساعد، والمدرس) الجدول (5)،(استاذ مساعد، واستاذ) الجدول (6) جاءت النتائج كما يلي:-

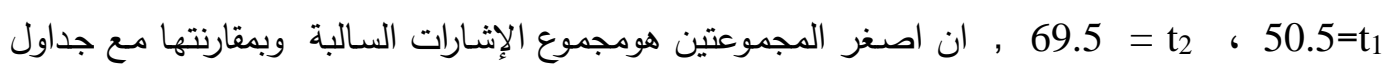

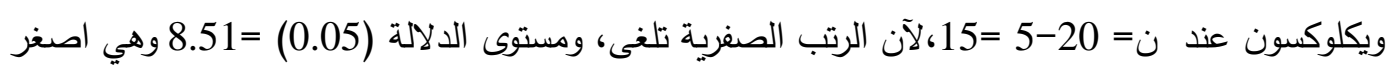

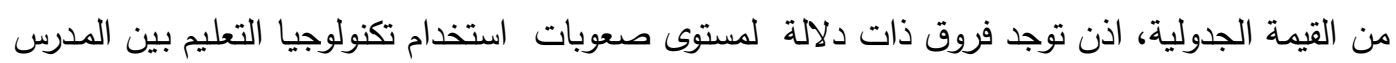
المساعد والمدرس.

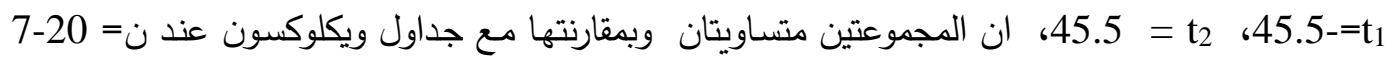

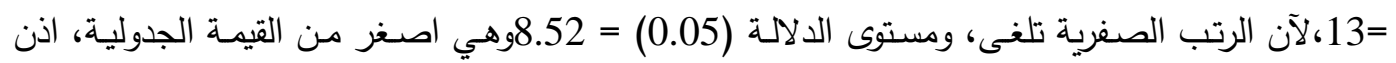

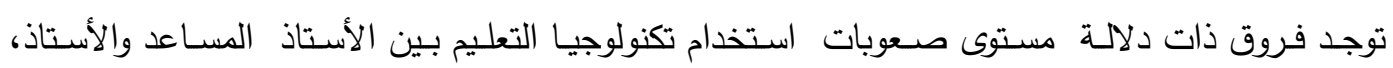
وبالتالي توجد فروق تعزى لمتغير المؤهل العلمي. 
جدول(6): خطوات اختبار ويكولكسون

جدول(5): خطوات اختبار ويكولكسون

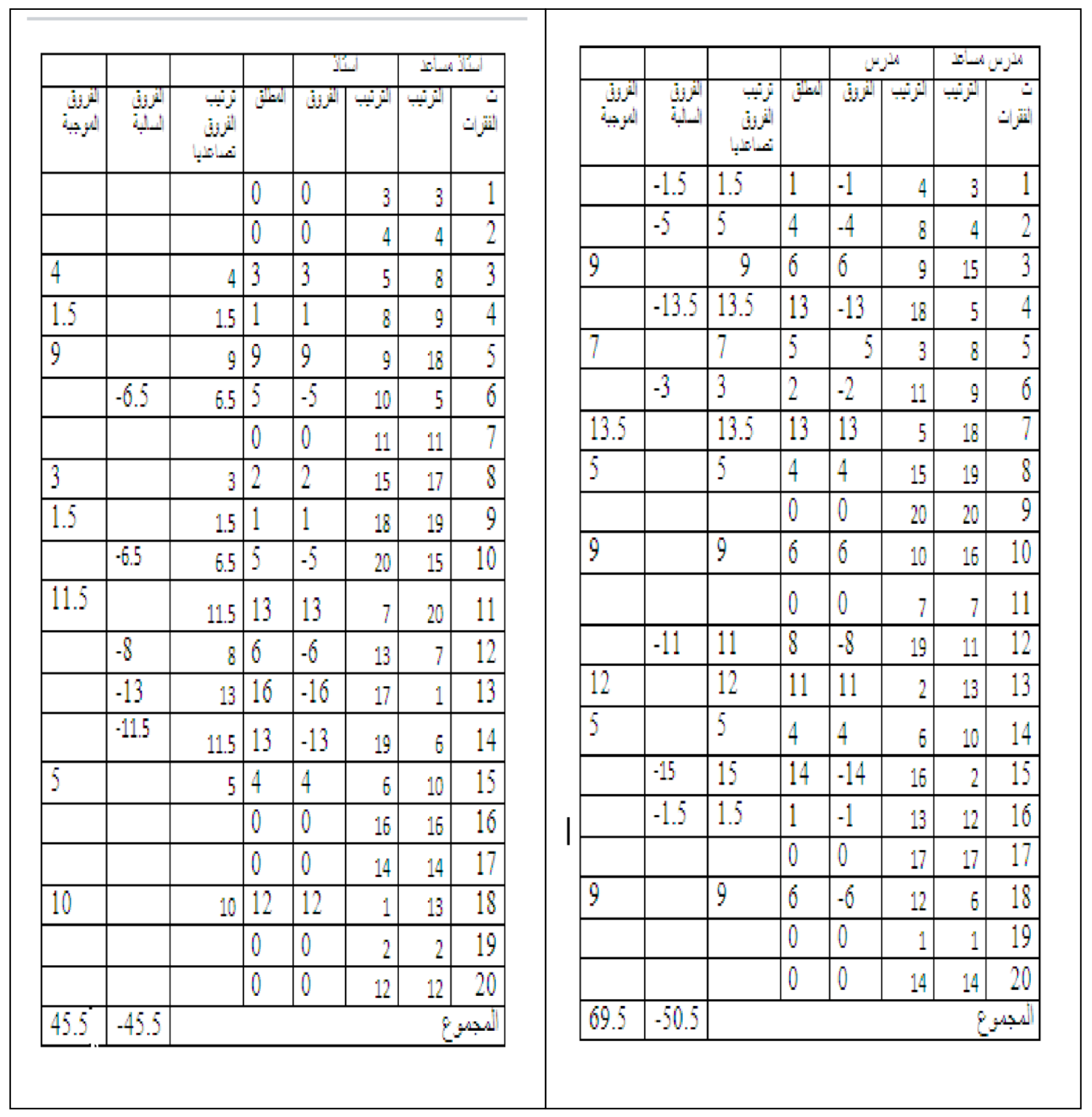

3) للتعرف على متوسط الفروق لصعوبات استخدام تكنولوجيا التعليم في التدريس الجامعي من وجهة نظر اعضاء الهيئة التدريسية وفقا لـتغير المؤهل الأكاديمي اظهر التحليل الإحصائي للبيانات بان الصعوبات توزعت كما في الجدول التالئي: 
تم حساب الوسط المرجح والوزن المئوي لصعوبات استخدام تكنولوجيا التعليم من وجهة نظر أعضاء هيئة التدريس(عينة البحث) وذلك بحسب متغير المؤهل الأكاديمي،وبإستخدام اختبار ويكلوكسون فجاءت النتائج كما هي موضحة في الجداول(7)، (8).

جلول(8):خطوات اختبار ويكولكسون جدول(7):ترتيب الصعوبات والأوزان المئوية بحسب متغير المؤهل الأكاديمي

\begin{tabular}{|c|c|c|c|c|c|c|c|}
\hline & & & & \multicolumn{2}{|c|}{ " } & \multicolumn{2}{|c|}{ 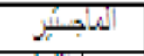 } \\
\hline النزئنة & 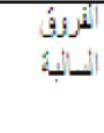 & 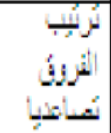 & 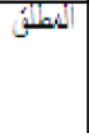 & |أنزئف & | & - & \begin{tabular}{r|} 
\\
\\
4 \\
4 \\
4
\end{tabular} \\
\hline 15 & & 15 & 16 & 16 & 3 & 19 & 1 \\
\hline 14 & & 14 & 14 & 14 & 4 & 16 & 2 \\
\hline 0 & & لبلنى & 0 & 0 & 5 & 5 & 3 \\
\hline \multirow[t]{2}{*}{10} & & 10 & 9 & 9 & 9 & 18 & 4 \\
\hline & -4.5 & 4.5 & 5 & -5 & 8 & 3 & 5 \\
\hline \multirow[t]{4}{*}{3} & & 3 & 4 & 4 & 11 & 15 & 6 \\
\hline & -7.5 & 7.5 & 7 & -7 & 18 & 11 & 7 \\
\hline & -14 & 14 & 14 & -14 & 19 & 5 & 8 \\
\hline & -9 & 9 & 8 & -8 & 15 & 7 & 9 \\
\hline 6.5 & & 6.5 & 6 & 6 & 10 & 16 & 10 \\
\hline 0 & & بلْنى & 0 & 0 & 20 & 20 & 11 \\
\hline 2 & & 2 & 3 & 3 & 7 & 10 & 12 \\
\hline 0 & & بلكتي & 0 & 0 & 17 & 17 & 13 \\
\hline 7.5 & & 7.5 & 7 & 7 & 6 & 13 & 14 \\
\hline \multirow[t]{2}{*}{4.5} & & 4.5 & 5 & 5 & 1 & 6 & 15 \\
\hline & -14 & 14 & 14 & -14 & 16 & 2 & 16 \\
\hline 6.5 & & 6.5 & 6 & 6 & 13 & 19 & 17 \\
\hline \multirow[t]{2}{*}{11} & & 11 & 10 & 10 & 2 & 12 & 18 \\
\hline & -12 & 12 & 13 & -13 & 14 & 1 & 19 \\
\hline 1 & & 1 & 2 & 2 & 12 & 14 & 20 \\
\hline 81 & -61 & & & & & & آلهجن \\
\hline
\end{tabular}

\begin{tabular}{|c|c|c|c|c|}
\hline \multicolumn{2}{|c|}{ 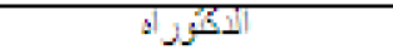 } & \multicolumn{2}{|c|}{ 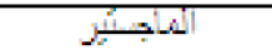 } & \\
\hline 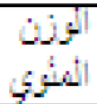 & in & الثئزئ & | & \\
\hline 99 & فترن 35 & 99 & فئز5 & 1 \\
\hline 99 & فترنة & 96 & فتزئ & 2 \\
\hline 98 & فقرد5 & 95.5 & فقزئو & 3 \\
\hline 98 & فترن & 93 & فتز & 4 \\
\hline 97.6 & 85 & 88 & 35 & 5 \\
\hline 92 & فتزدئ & 88 & فقزرة & 6 \\
\hline 92 & فترك5 & 84 & فقردمأم & 7 \\
\hline 91 & فتردئ & 81 & فئرد & 8 \\
\hline 88 & فترد5 & 80 & فقزة:78 & 9 \\
\hline 87 & فترنم & 76 & ف ف & 10 \\
\hline 85 & فقزئك & 73 & فقزمئ20 & 11 \\
\hline 79 & فترك 75 & 68 & فقزمة & 12 \\
\hline 74 & فتر5 & 67 & فقرة: & 13 \\
\hline 70 & 65 & 65 & فقرة & 14 \\
\hline 68 & فترثئ & 64 & 65 & 15 \\
\hline 63 & ف & 63 & فتر & 16 \\
\hline 62 & فتر5 & 63 & فقرد & 17 \\
\hline 60 & ف فرد 2 & 61 & فقزمة & 18 \\
\hline 54 & فتردة 14 & 52 & فقرك 15 & 19 \\
\hline 49 & فتر & 44 & فترنة & 20 \\
\hline
\end{tabular}




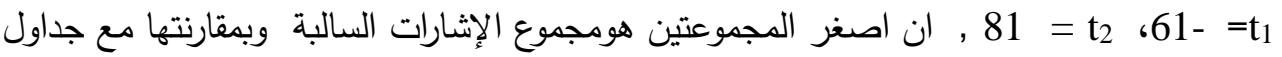
ويكلوكسون عند ن=20 -3= 17، لآن الرتب الصفرية تلغى، ومستوى الدلالة (0.05) = 8.47 وهي اصغر من القيمة الجدولية، اذن توجد فروق ذات دلالة تعزى لمتغير المؤهل الأكاديمي.

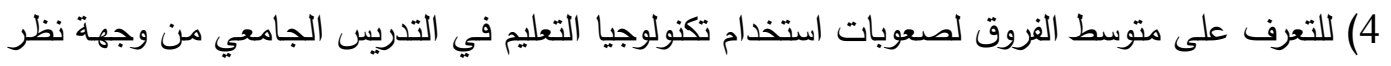
اعضاء الهيئة التدريسية وفقا لمتغير التخصص، تم حساب الوسط المرجح والوزن المئوي صعوبات استخدام

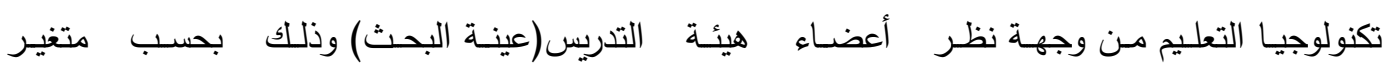
التخصص،وبإستخدام اختبار ويكلوكسون فجاءت النتائج كما هي موضحة في الجداول(9)، (10). جدول(10):خطوات اختبار ويكولكسون جدول(9): ترتيب الصعوبات والأوزان المئوية بحسب متغير التخصص

\begin{tabular}{|c|c|c|c|c|c|c|c|}
\hline & & & & \multicolumn{2}{|c|}{ "نر } & \multicolumn{2}{|c|}{ 年 } \\
\hline الزيزبة & 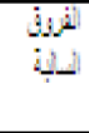 & 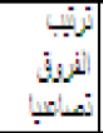 & Jall & أنزون & اترنب & اتزب & نتزرن \\
\hline 0 & & 0 & 0 & 0 & 4 & 4 & \\
\hline & -1.5 & 1.5 & 1 & -1 & 9 & 8 & \\
\hline & -85 & 8.5 & 5 & -5 & 8 & 3 & \\
\hline & 4 & 4 & 2 & -2 & 11 & 9 & \\
\hline 15 & & 15 & 15 & 15 & 3 & 18 & \\
\hline & -6 & 6 & 3 & -3 & 18 & 15 & $\theta$ \\
\hline 0 & & 0 & 0 & 0 & 5 & 5 & \\
\hline 13 & & 13 & 13 & 13 & 7 & 20 & 8 \\
\hline 7.5 & & 7.5 & 4 & 4 & 15 & 19 & \\
\hline 0 & & 0 & 0 & 0 & 10 & 10 & 1 \\
\hline & -12 & 12 & 11 & -11 & 19 & 7 & 11 \\
\hline & -14 & 14 & 14 & -14 & 20 & 6 & 1 \\
\hline & -1.5 & 1.5 & 1 & -1 & 17 & 16 & 1 \\
\hline 7.5 & & 7.5 & 4 & 4 & 13 & 17 & 1 \\
\hline & -8.5 & 8.5 & 5 & -5 & 16 & 11 & 1 \\
\hline 0 & & 0 & 0 & 0 & 2 & 2 & 1 \\
\hline 11 & & 11 & 7 & 7 & 6 & 13 & 1 \\
\hline 4 & & 4 & 2 & 2 & 12 & 14 & 1 \\
\hline 0 & & 0 & 0 & 0 & 4 & 1 & 1. \\
\hline 4 & 4 & 4 & 2 & -2 & 14 & 12 & 2 \\
\hline 62 & -60 & & & & & & بجن \\
\hline
\end{tabular}

\begin{tabular}{|c|c|c|c|c|}
\hline- & 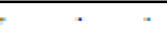 & - & -2 & \\
\hline S & 3 il & $r$ & & \\
\hline 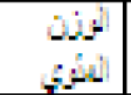 & زئ & أi & 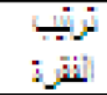 & : \\
\hline 98 & 4:i & 100 & 4: & 1 \\
\hline 69 & gi & 99 & 8: & 2 \\
\hline 49 & Bi & 98.5 & $3: j$ & 5 \\
\hline 39 & $11: 3$ & 89 & ف: & 4 \\
\hline 19 & 31 فi & 59 & 15: & $=$ \\
\hline 19 & 18: & 94 & $15: j$ & 0 \\
\hline 90 & فئi & 29 & $5: j$ & I \\
\hline 48 & $7 \dot{i}$ & 98 & 200 i & 8 \\
\hline 83 & 15: & 80 & ف: & 7 \\
\hline 50 & 100 & 77 & 100 & \\
\hline 97 & 19:-i & 74 & 72 & \\
\hline 78 & 200 i & 70 & ف: & \\
\hline 73 & $172 ;$ & 69 & $16: j$ & \\
\hline 72 & $13:$ & 68 & $17: j$ & \\
\hline 86 & $16: j$ & 61 & $11: j$ & \\
\hline 65 & 23 & 56 & $2: j$ & \\
\hline 65 & 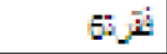 & 35 & 13: & \\
\hline 56 & 123 & 52 & 14:ji & \\
\hline 84 & $1: j$ & 51 & 13 & 10 \\
\hline 47 & 14: i & 51 & $125 \mathrm{j}$ & \\
\hline
\end{tabular}




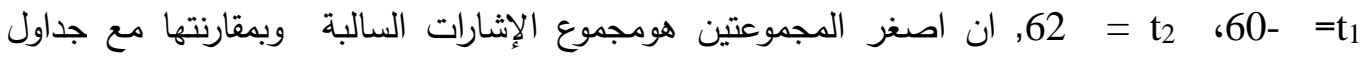
ويكلوكسون عند ن= 20-5=15،لآن الرتب الصفرية تلغى، ومستوى الدلالة (0.05) = 8.47 وهي الإنتارت اصغر من القيمة الجدولية، اذن توجد فروق ذات دلالة تعزى لمتغير التخصص.

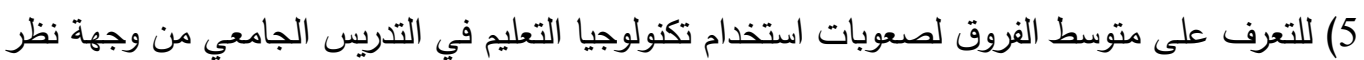
اعضاء الهيئة التدريسية وفقا لمتغير سنوات الخبرة،تم حساب الوسط المرجح والوزن المئوي لصعوبات استخدام تكنولوجيا التعليم من وجهة نظر أعضاء هيئة التدريس(عينة البحث) وذللك بحسب متغير سنوابت التهات

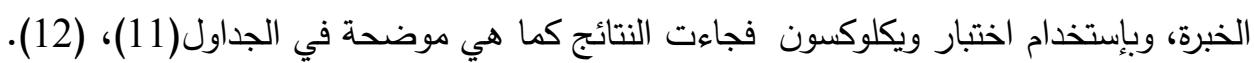
جدول(12) خطوات اختبار ويكولكسون جدول(11) ترتيب الصعوبات والأوزان المئوية بحسب متغير سنوات الخبرة

\begin{tabular}{|c|c|c|c|c|c|c|c|}
\hline \multicolumn{8}{|c|}{$\alpha \alpha$} \\
\hline \multirow{3}{*}{$\frac{j^{2}}{4}$} & \multirow{3}{*}{$\begin{array}{l}4 \\
\\
4\end{array}$} & \multirow{3}{*}{$\begin{array}{l}4 \\
3 \\
3 \\
4\end{array}$} & \multirow{3}{*}{ itu } & \multicolumn{2}{|c|}{$382-6$} & \multicolumn{2}{|c|}{$d-51$} \\
\hline & & & & 54 & 4 & ivi & \\
\hline & & & & & & & التزرة \\
\hline \multirow[t]{3}{*}{6} & & 6 & 5 & 5 & 4 & 9 & 1 \\
\hline & 5 & $j$ & 4 & 4 & 8 & 4 & 2 \\
\hline & .1 .5 & 1.5 & 1 & -1 & 9 & 8 & 3 \\
\hline \multirow[t]{2}{*}{13} & & 13 & 12 & 12 & 3 & 15 & 4 \\
\hline & -8 & 8 & 7 & .7 & 18 & 11 & 1 \\
\hline 15 & & 15 & 13 & 13 & 5 & 18 & 6 \\
\hline \multirow[t]{3}{*}{7} & & 1 & 6 & .6 & 11 & 5 & 7 \\
\hline & .13 & 13 & 12 & .12 & 1.5 & 3 & 8 \\
\hline & -1.5 & 1.5 & 1 & .1 & 20 & 18 & 9 \\
\hline \multirow[t]{3}{*}{4} & & 4 & 3 & 3 & 7 & 10 & 10 \\
\hline & .10 & 10 & 9 & .9 & 10 & 1 & 11 \\
\hline & .13 & 13 & 12 & .12 & 19 & 7 & 12 \\
\hline 0 & & 0 & 0 & 0 & 17 & 17 & 13 \\
\hline \multirow[t]{2}{*}{17} & & 17 & 14 & 14 & 6 & 20 & 14 \\
\hline & .17 & 17 & 14 & .14 & 16 & 7 & 15 \\
\hline 0 & & 0 & 0 & 0 & 13 & 13 & 16 \\
\hline 17 & & 17 & 14 & 14 & 2 & 16 & 17 \\
\hline 11 & & 11 & 11 & 11 & 1 & 12 & 18 \\
\hline \multirow[t]{2}{*}{3} & & 3 & 2 & 2 & 12 & 14 & 19 \\
\hline & 9 & 9 & 8 & 8 & 14 & 6 & 20 \\
\hline 93 & .78 & & & & & & الجنابو \\
\hline
\end{tabular}

\begin{tabular}{|c|c|c|c|c|}
\hline \multicolumn{2}{|c|}{$j \mathrm{~B}-\mathrm{i}$} & \multicolumn{2}{|c|}{$2-5-1$} & \multirow[b]{2}{*}{ هن } \\
\hline ئit & : & $\begin{array}{l}0 j \\
4 \\
4\end{array}$ & $\begin{array}{l}+j \\
3 \\
3\end{array}$ & \\
\hline 99 & $4: 3$ & 100 & git & \\
\hline 79 & $\mathrm{Bi}$ & 97 & 4 & 2 \\
\hline 96 & $9:$ i & 97 & Bi & 9 \\
\hline 94 & 30 & 97 & $15 i$ & 4 \\
\hline 92 & $1 \mathrm{~B}$ & 94 & $111 \mathrm{i}$ & \\
\hline 18 & 5. & 84 & $18 \mathrm{i}$ & \\
\hline 88 & $11: 3$ & 29 & 5 & \\
\hline 87 & $15: j$ & 98 & 3 & \\
\hline 48 & 200. & 98 & 19: & \\
\hline 80 & $7: 3$ & 83 & $10 ;$ & \\
\hline 97 & $10 . j$ & 87 & 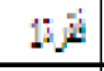 & \\
\hline 78 & $19: 3$ & 87 & $7 a j$ & \\
\hline 70 & $172 i$ & 87 & $17 \mathrm{~h}$ & \\
\hline 69 & 63 & 87 & 200 & \\
\hline 69 & $16: j$ & 72 & $2 i$ & \\
\hline 26 & $13: 3$ & 72 & 133 & \\
\hline 60 & 23 & 69 & $16 . \mathrm{i}$ & \\
\hline 55 & $13: i$ & 61 & $12 \mathrm{i}$ & \\
\hline 53 & $12: 3$ & 58 & $14: i$ & \\
\hline 49 & $14 ;$ & 65 & 6.1 & \\
\hline
\end{tabular}


93 = t2 ان اصغر المجموعتين هومجموع الإثارات السالبة وبمقارنتها مع جداول

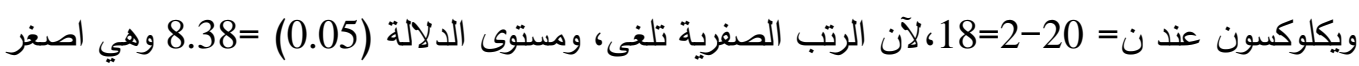
من القيمة الجدولية،اذن توجد فروق ذات دلالة تعزى لمتغير التخصص.

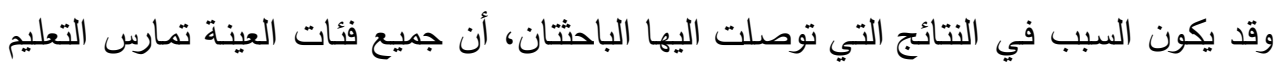
الجامعي تحت نفس الظروف من عدم توفر بعض تكنولوجيا التعليم وعدم تلق دورات تدريبية على استخدام

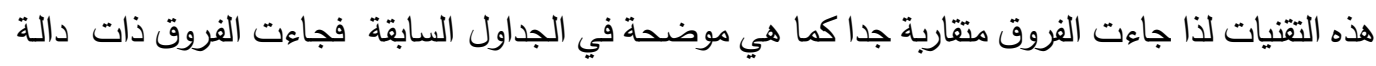
إحصائيا. 11- التوصيات والمقترحات

1)أن تهتم إدارة الكليات او الجامعات باستخدام التقنية الحديثة في التدريس وأن يكون الهدف الأول من التقنية هو استخدامها كأسلوب تعليمي، لا لتكون هي ذاتها موضوعاً للتعلم.

2) ضرورة عقد الدو رات التدريبية لأعضاء هيئة التدريس في التعليم تختص بكيفية داتئية استخدام التقنيات الحديثة

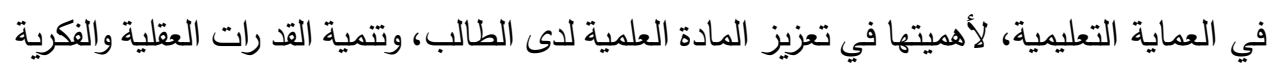

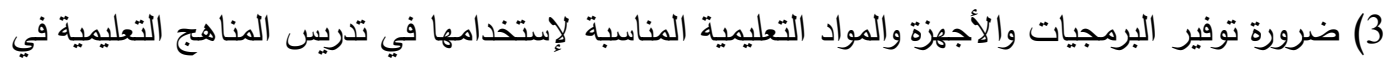
جميع الكليات والجامعات، والتي تساعد أعضاء هيئة التدريس على استخدام التكنولوجيا وان تكون

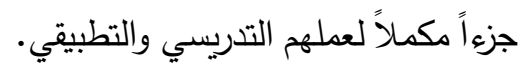
4)إنشاء مراكز للوسائل التعليمية في الكليات يضم الحد الأدنى من معينات تكنولوجيا التعليم والمستلزمات المطلوبة لتصنيع الوسائل التعليمية وتصميم البرامج التعليمية. 5)تتبنى إدارة الكليات أهمية استخدام تكنولوجيا التعليم في تتمية المها رات ومعاونة أعضاء هيئة التدريس على لئي اختصار الوقت والجهد لإيصال المادة العلمية للطالب ويكون ذلك من خلال توجيهات واضحة وملزمة التئه باستخدام تكنولوجيا التعليم.

6) العمل على رفع درجة معرفة اعضاء هيئة التدريس في الجامعات لاستخدام تقنيات التعليم عن طريق:

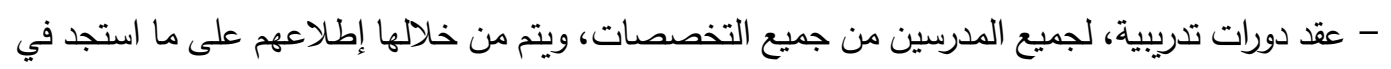
مجال استخدام تقنيات التعليم.

- ضرورة الاستعانة ببعض الخبراء و المختصين بعملية التدريب على استخدام مستحدثات تكنولوجيا

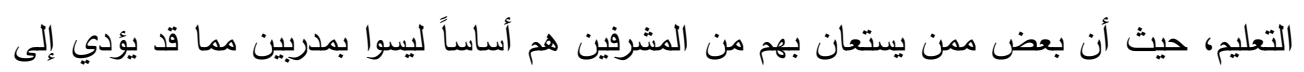
تحويل عملية التدريب في بعض الدورات إلى مجرد محاضرة غير فعالة.

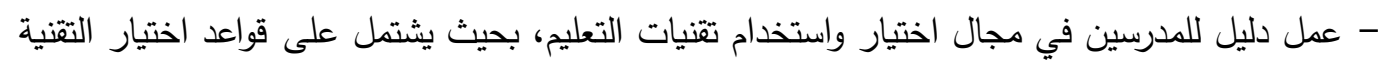
التعليمية من حيث محتواها، كذلك القواعد التي يجب مراعاتها قبيل استخدامها وبعدها وفي اثنائها. 


\section{CONFLICT OF INTERESTS.}

There are non-conflicts of interest.

$$
12
$$

[1] نشـوان، يعقوب حسـين، المـنهج التربـوي مـن منظـور إسـلامي، عمـان، دار الفرقـان، ص12-14،

[2]خميس، محمد عطية، منتوجات تكنولوجيا التعليم، دار الكلمة ط 1, القاهرة، ص،18، صا، 2003.

[3]أبو النور ، منصور، المعلم والطالب، القاهرة:دار النهضة العربية، ص233، 233

[4] http://www.dahsha.com/viewarticle.php?id=27831

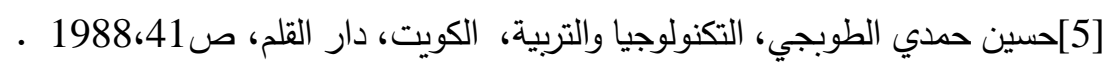

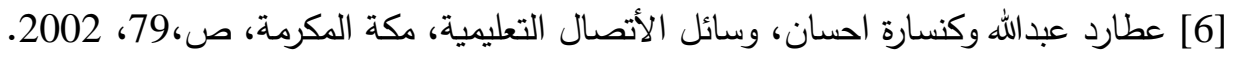

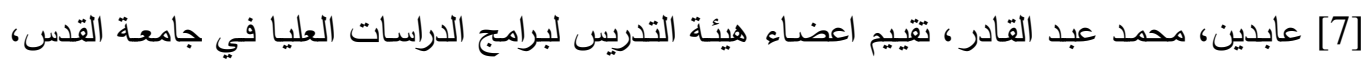

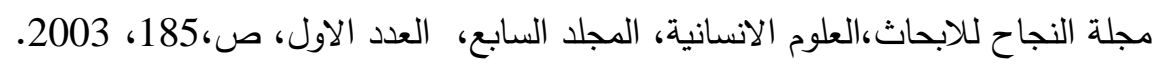

[8] العريشي، جبريل حسن، وهند العروان، الدور المعلوماتي لعضو هيئة التدريس في البيئة الاكاديمية،

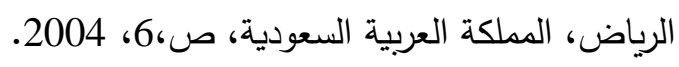

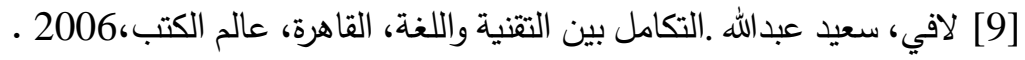

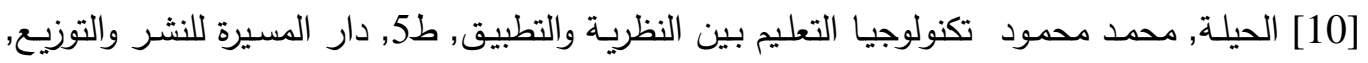

$$
\text { عمان، ص،24، } 2007 .
$$

[11] سـلامة،عبدالحافظ بـن محمد والدايل، سـعد بـن عبدالرحمن، مدخل إلى تكنولوجيا التعليم،الطبعـة

$$
\text { الرابعة، الرياض، دار الخريجي للنشر والتوزيع، ص، 11، 11، } 2008 \text { م. }
$$

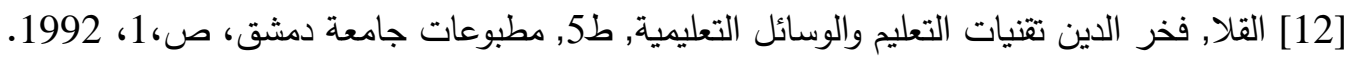

[13] الخطيب, محمد لطفي "اتجاهـات المعلمين في محافظـة اربـ نحوتكنولوجيا التعليم "،مجلـة العلوم

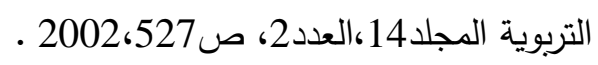

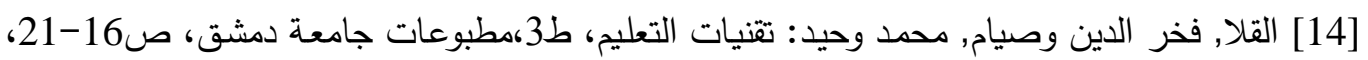

$$
.2004
$$

[15] http://www.id4arab.com/2013/08/blog-post.html\#.V0HUr5wZH6h

[16] ) كنسارة، احسان بن محمد وعطار ، عبدالله بن اسحاق، الحاسب الآلي وبرمجيات الوسائط، الطبعة

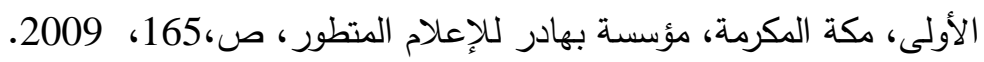

[17] سرحان محمد مرسي " اتجاهات معلمي المواد العلمية في المرحلة الثانوية نحو تكنولوجيا التعليم في لهي

مديرية التربية والتعليم لمنطقة عمان الكبرى الأولى، رسالة ماجستير ،غير منشورة، الجامعة الأردنية:

$$
\text { كلية التربية، } 1993 .
$$

[18] Smith, K. J.,the Relationships between the Attitudes of Teachers Secondary Technology and seven Independent Factors, Diss Abs. Int. Vol. 56-03A, 1996.

[19]Khazaleh, T. And Jawarneh, T., Barriers to effective information technology integration in Jordanian schools as perceived by in-service teachers. Jordan Journal of Educational Sciences 2(4): 281-29z،2006. 
Journal of University of Babylon, Pure and Applied Sciences, Vol.(27), No.(1): 2019

[20] العمايرة، محمد حسن, آراء معلمي بعض مدارس وكالة الغوث الدولية/الأردن في أهمية استخدام

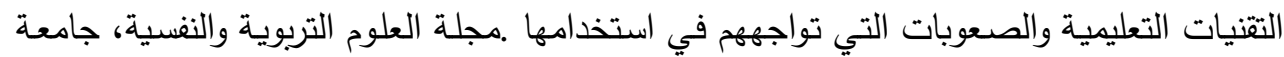

$$
\text { البحرين، ص، 135- 2003، 164. }
$$

[21] عبيدات، ذوقان وآخرون، البحث العلهي “، مفهومه وأدواته وأساليبه، ، الرياض، دار أسامة، ص، 274، 2003 م.

وهيب مجيد “ الاحصاء التطبيقي في العلوم الاجتماعية”، ص246-247، بيروت، 2010. 


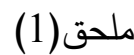

بسم الله الرحمن الرحبم

$$
\text { كلبة التزربية الاستعاسية المستصرية }
$$

م/ اسنطلاع اراء الخبراء

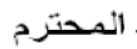

حضرة الأستاذد / الأستاذ

بين يديكم أسثببان للبحث بعنو ان (صعوبات تطبيث تكثونوجيا التطيم الحذيثة

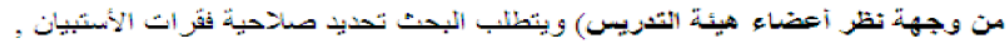

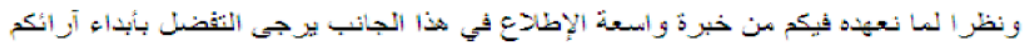

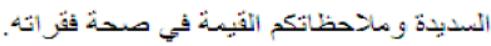

و'كم جزيل الثكر وانتقدير

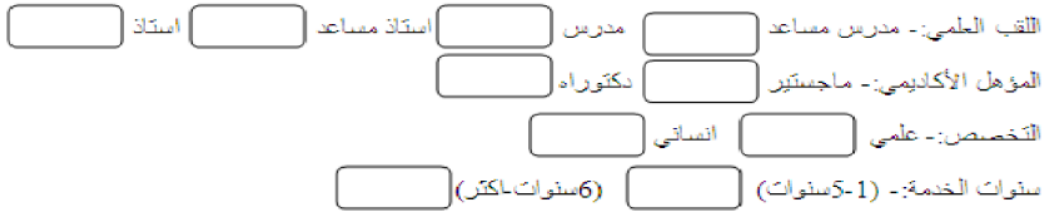

\begin{tabular}{|c|c|c|c|c|}
\hline Y5 & إنبا & تحت & التصبعوبات- & 二 \\
\hline & & & 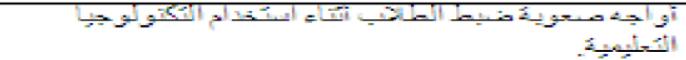 & 1 \\
\hline & & & 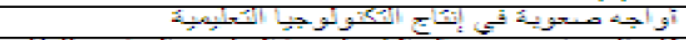 & 2 \\
\hline & & & 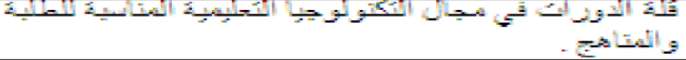 & 3 \\
\hline & & & 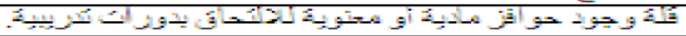 & 4 \\
\hline & & & 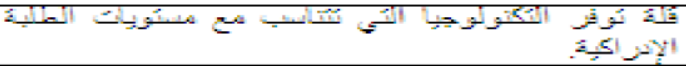 & 5 \\
\hline & & & 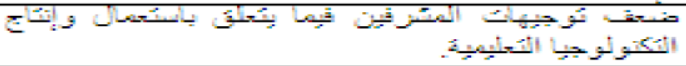 & 6 \\
\hline & & & 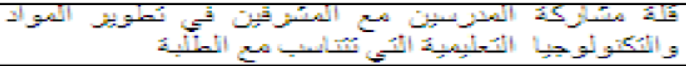 & 7 \\
\hline & & & 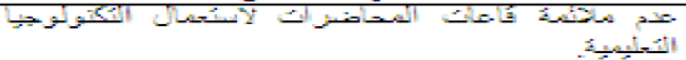 & 8 \\
\hline & & & 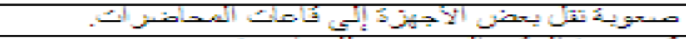 & 9 \\
\hline & & & 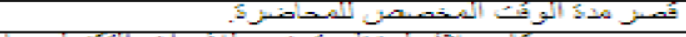 & 10 \\
\hline & & & 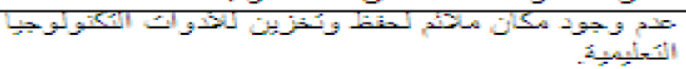 & 11 \\
\hline & & & 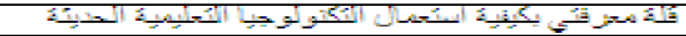 & 12 \\
\hline & & & 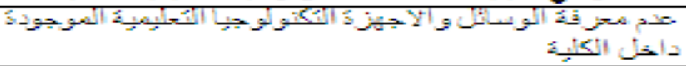 & 13 \\
\hline & & & 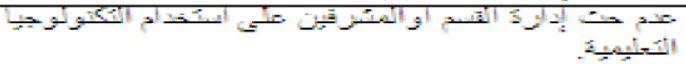 & 14 \\
\hline & & & 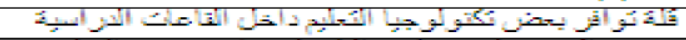 & 15 \\
\hline & & & 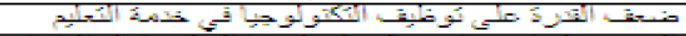 & 16 \\
\hline & & & 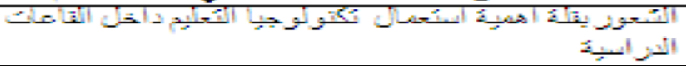 & 17 \\
\hline & & & 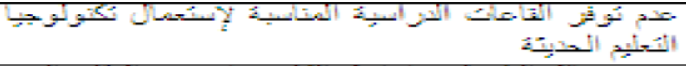 & 18 \\
\hline & & & 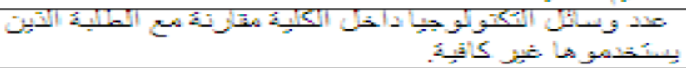 & 19 \\
\hline & & & 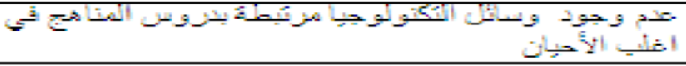 & 20 \\
\hline
\end{tabular}

ما الصعوبات التي تحول دون الاستعمال الفعال من اعضاء هيئة التدريس للتكنولوجيا التعليمية في القاعات الدراسيه (المحاضرات).الرجاء وضع علامة (ل) أمام كل فقرة في الحقل الذي يمثل رأيك: 